\title{
Mhin-mit-79-64-0001 MLM-MU-79-64-0001
}

RECEIVED

JUL 011996

QSTI

\section{MOUND FACILITY}

978 ANNUAL REPORT

DISTRIBUTON OF THIS DOCUNIENT IS UNLRMTED 


\section{DISCLAIMER}

This report was prepared as an account of work sponsored by an agency of the United States Government. Neither the United States Government nor any agency thereof, nor any of their employees, makes any warranty, express or implied, or assumes any legal liability or responsibility for the accuracy, completeness, or usefulness of any information, apparatus, product, or process disclosed, or represents that its use would not infringe privately owned rights. Reference herein to any specific commercial product, process, or service by trade name, trademark, manufacturer, or otherwise does not necessarily constitute or imply its endorsement, recommendation, or favoring by the United States Government or any agency thereof. The views and opinions of authors expressed herein do not necessarily state or reflect those of the United States Government or any agency thereof. 


\section{8}

\section{Another year of progress, new milestones}

For Mound Facility, the year 1978 was one of progress marked by enhanced mission assignments and significant milestones. The thirtieth anniversary of the site was celebrated in October, and Monsanto Research Corporation began a new 5-year contract to operate the Facility for the Department of Energy (DOE). Longstanding production assignments were strengthened, and we were given a new responsibility: to develop and produce all ceramic parts used in Mound-built products. Progress toward U. S. energy objectives was bolstered by Mound programs supporting the development of nuclear fusion power, unlocking previously unattainable fossil fuels, ensuring the safety and security of nuclear material handling operations, and exploring the real promise of energy from the sun. In 1978 we focused our attention on many efforts aimed at a brighter, more secure future for us all ... 


\section{Energy}

\section{Fossil Fuels Research}

\section{Unlocking natural gas from shale} deposits deep underground and finding ways to wring energy from thin, unmineable seams of coal are two of the many areas in which we have made progress in 1978.

Devonian shale, which is found as much as 8,000 feet underground, contains a significant amount of natural gas that could enhance U.S. energy reserves. In 1978, we established the differences between the shale deposits found in the Illinois and Appalachian basins, and charted the zones of highest gas concentration in preparation for the drilling of two wells in 1979.

Burning coal underground, "in-situ," could be a way to utilize the large amount of U.S. coal that can't easily be brought to the surface. Mound continued its preparation for an experimental underground burn at Pricetown, West Virginia, with final design and fabrication of all analytical, analog, and data acquisition equipment needed at the site. The tricky job of positioning instrumentation accurately 900 feet "down hole" was successfully completed.

Our expertise in the development of coal gasification systems was rec- ognized with a request from the Morgantown Energy Technology Center for engineering and economic assessment help on the new Hygas coal gasification process. Hygas is a method for production of high-Btu content, clean-burning fuel gas from coal - not unlike methods used in other coal gasification projects in which we have participated.

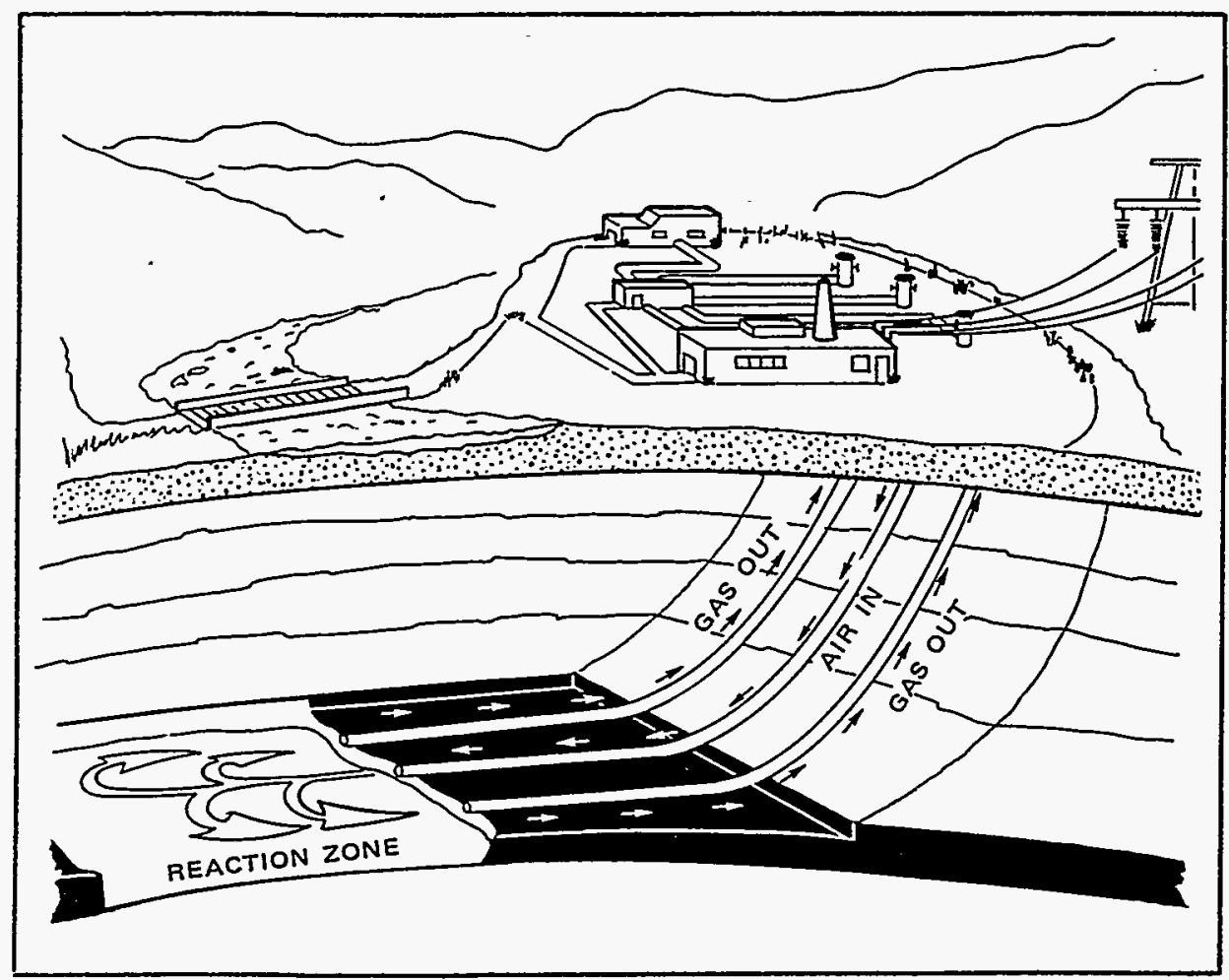

Power generating stations such as this may one day make use of thin seams of coal locked deep beneath the surface. 


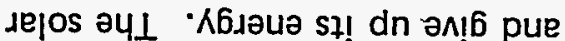

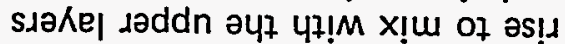

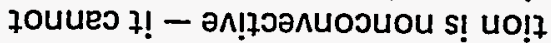

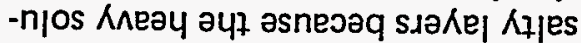

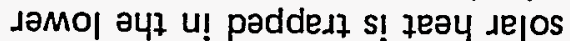

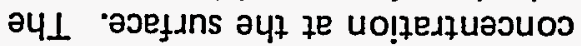

7jes quasdad $\lfloor$ ueył ssa U! bu!fjns

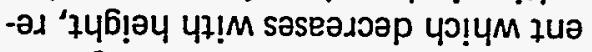
-!pes6 e sMol|아 znq 'wsof! un zou s!

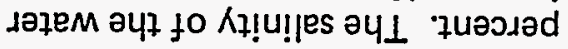

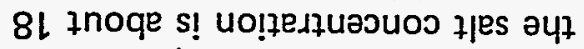

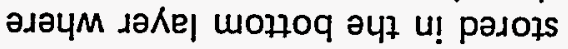
s! 7eay s,puod ay fo łsow 7EaY

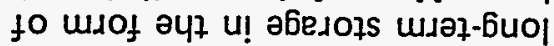
pue Uo!?Ja||OJ ᄉ6jaua de|OS 7SOJ-MO|

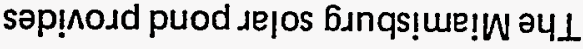

- Nuensqoy u!

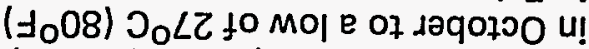

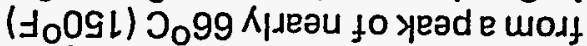
sabued puod daəp-700f-0L әप7 fo

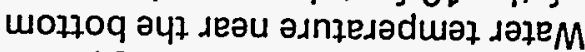
jood bu!um!ns pue bu!p!!nq uo!?e

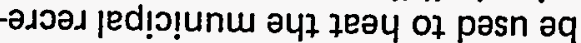

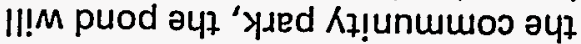

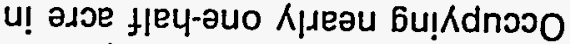
spuod de|Os qua!ped6-zןes bu!»yoM

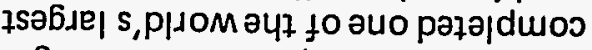
6snqs!ue! $W$ to 17 ! ว punow to dןaप aपl प?!M '8L6L U।

\section{кб઼ıиョ rejos}

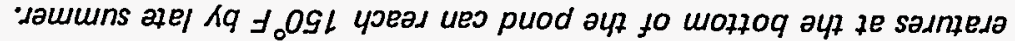

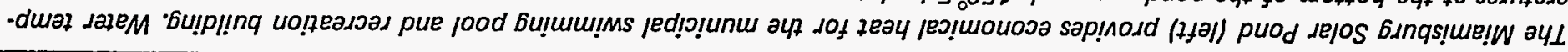

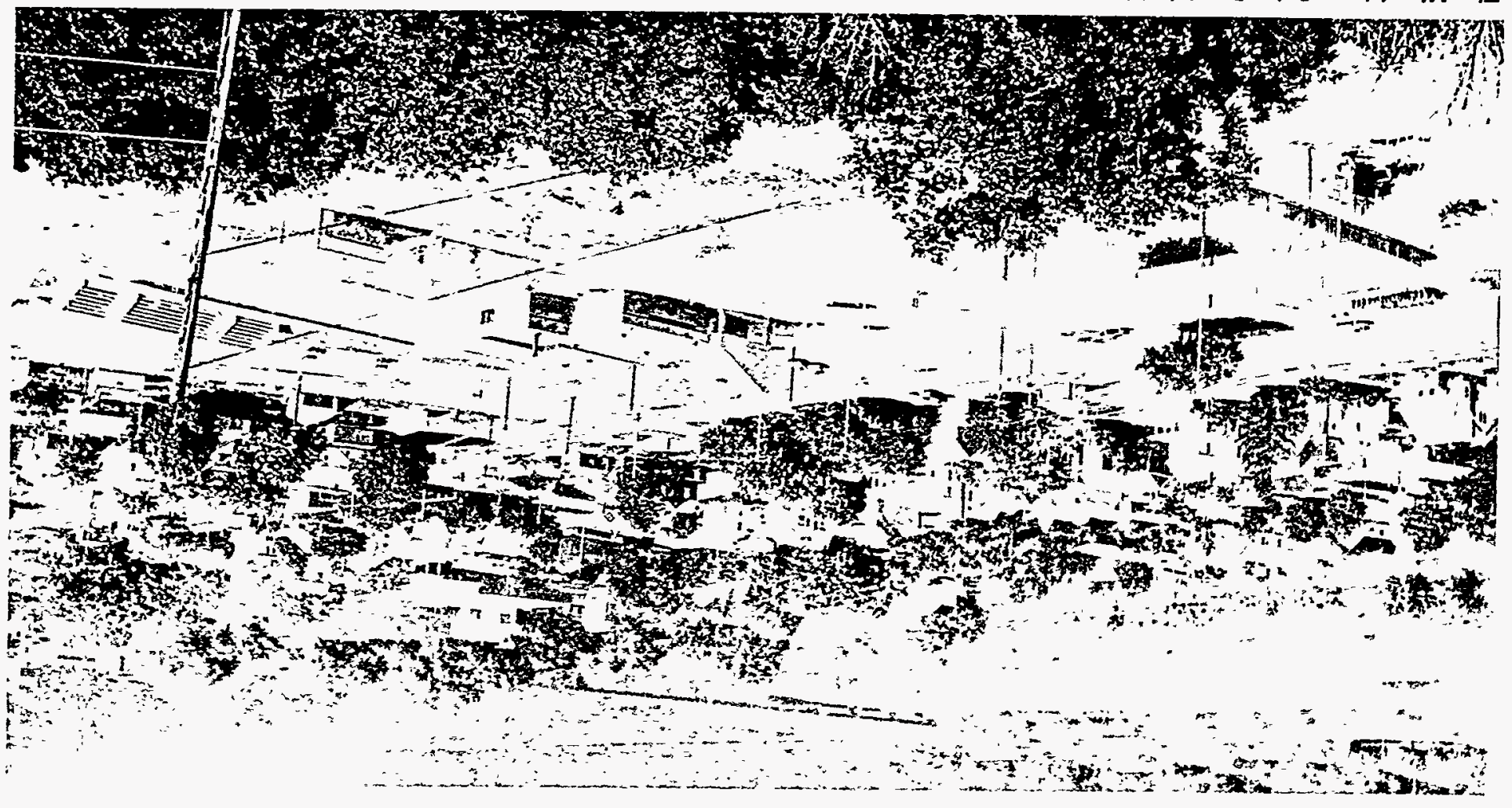




\section{Energy}

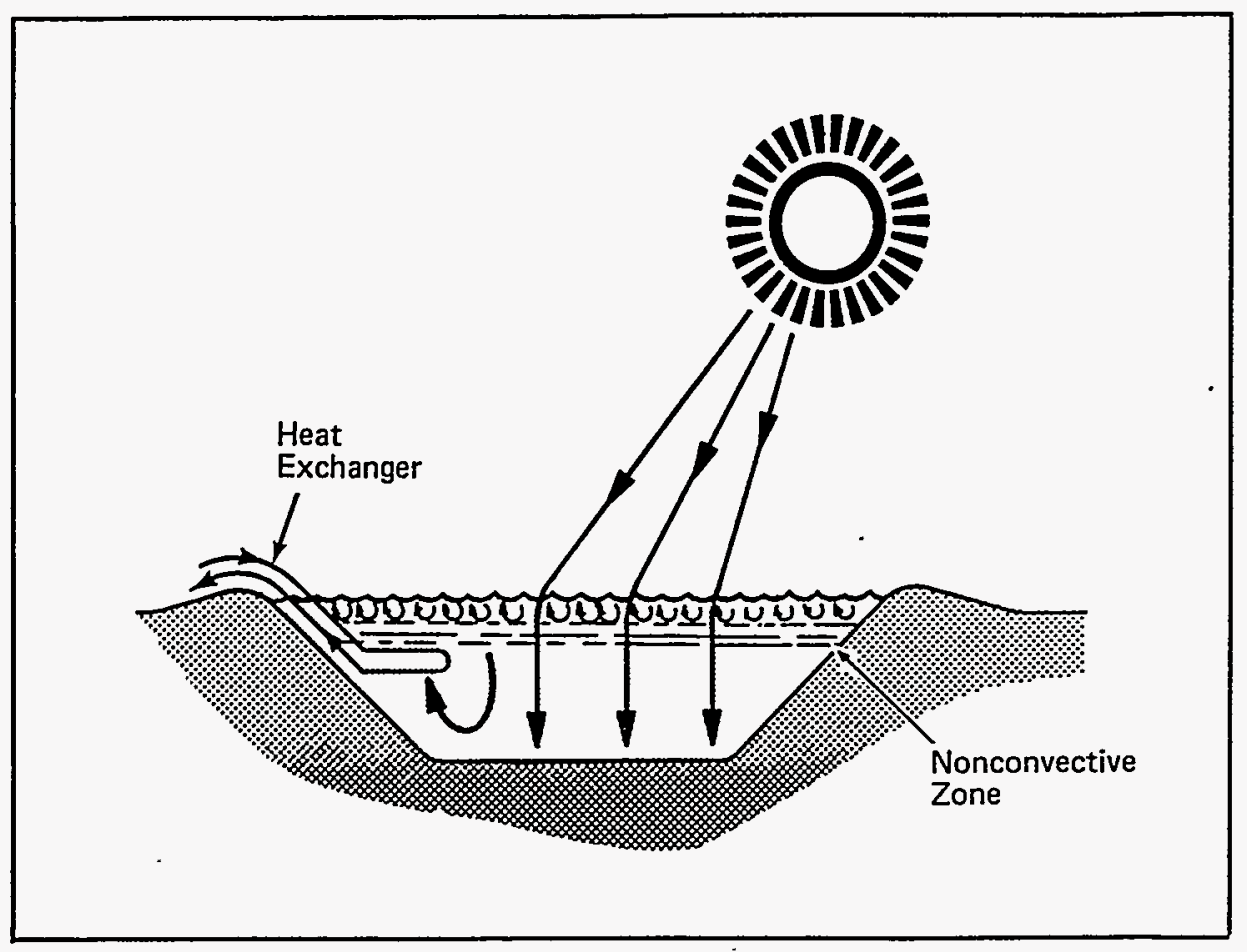

pond contains 1,100 tons of salt dissolved in 1,400,000 gallons of water. A heavy plastic liner protects the soil beneath the pond from this high concentration of salt.

Heat is removed by water flowing through a copper tube heat exchanger located in the solar pond.
Heat extraction has been conservatively estimated at $10 \%$ of the annual solar radiation received. Total construction cost was approximately $\$ 70,000$ (\$3.20/sq.ft.), which makes the solar pond one of the lowest cost energy collectors. If the cost of the pond is amortized over its predicted 10-12-year life, the cost of the heat is $2.7 \mathrm{~d} / \mathrm{kW} \mathrm{hr.,} \mathrm{competi-}$ tive with the escalating cost of fuel oil.

We are also pursuing studies for the U.S. Department of Energy on solar energy collection fluids for use at temperatures above the boiling point of water. Most solar collectors use the sun to heat metal tubing which then transfers the heat to a circulating fluid. Mound is developing a more efficient method in which the transfer fluid is heated directly as it flows through transparent tubing. In order to make this method work, our researchers are examining different high boiling heat transfer fluids containing solar radiation-absorbing dyes, called chromophores, to find combinations that are relatively easy to produce and do not break down at high temperatures. Our work in this new area could result in more efficient solar collectors that can reduce our dependence on fossil fuels for energy.

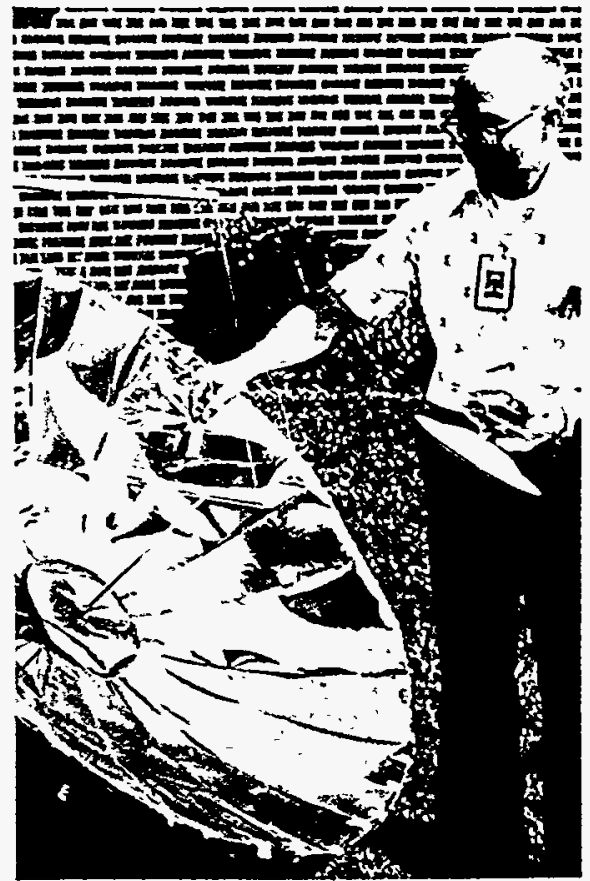

Rod Bowser fries hot dogs at the focus of a homemade solar reflector to commemorate the first annual Sun Day, May 3, 1978. 


\section{Hydride Research}

Future use of clean-burning hydrogen as a replacement for fossil fuels depends, in part, on an efficient means of storing the light gas. Some of our work for the DOE Office of Basic Energy Sciences is aimed at determining the fundamental characteristics of a promising group of hydrogen storage materials: metal hydrides.
Because forms of iron, titanium, and certain other metals can be made to chemically combine with hydrogen, then release it on demand at moderate pressure, containers of these hydrides are considered by many to be safer than high pressure tanks for mobile hydrogen applications.

Researchers in West Germany have been monitoring hydrogen-powered test vans equipped with hydride tanks for several years, and advocate converting city transportation to the system.

Current research at Mound is directed at revealing factors that affect the diffusion behavior (rate of hydrogen production) of hydrides such as the TiFe-TiFeH system. Improvement of diffusion characteristics by the addition of various alloys is of special interest.

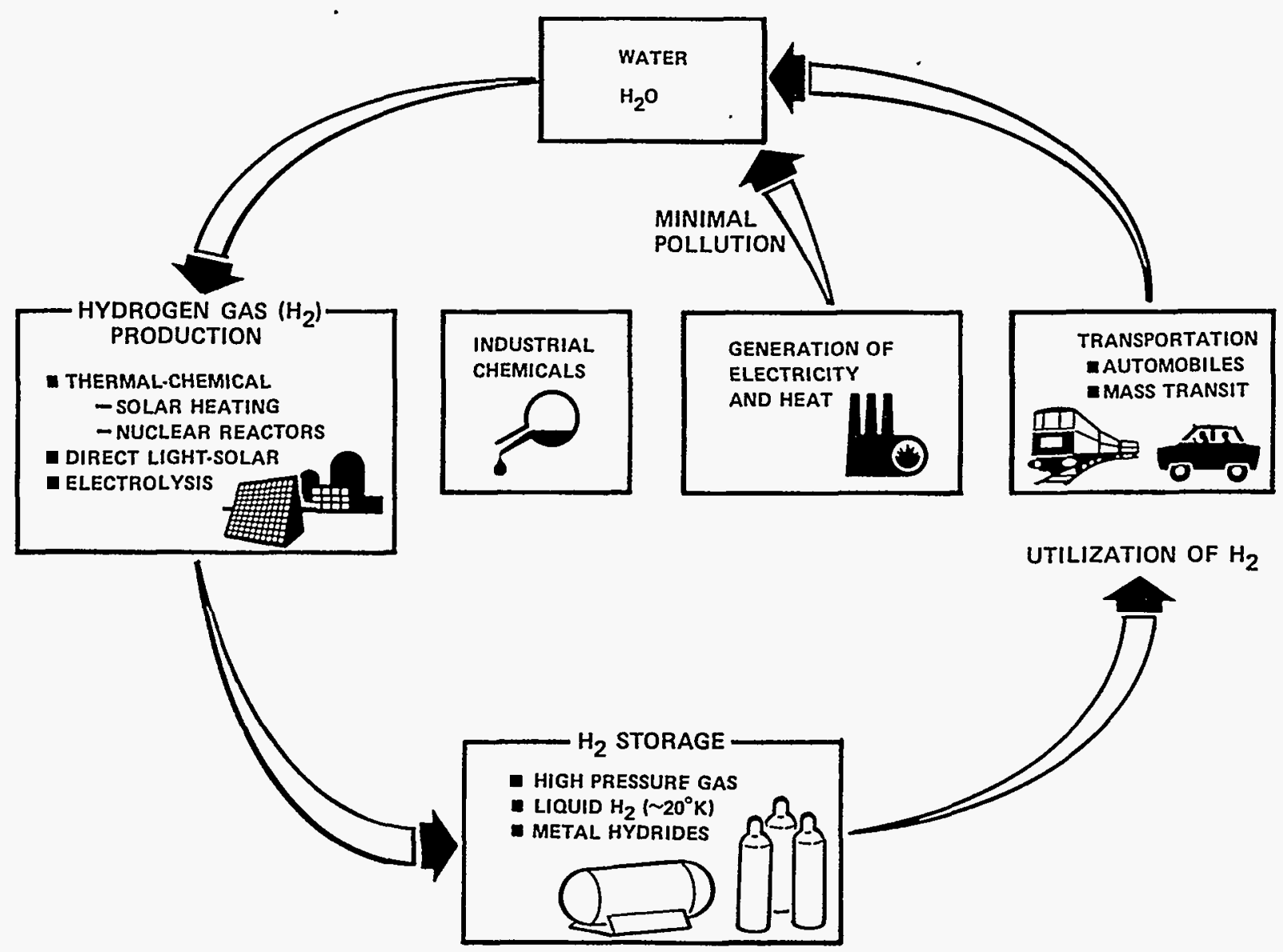




\section{Energy}

\section{Fusion}

In October 1978, Mound was chosen by Princeton University's Plasma Physics Laboratory to provide a tritium storage and delivery system (TSDS) for the Tokamak Fusion Test Reactor now under construction.

The Princeton reactor will be the first magnetically confined fusion reactor to use deuterium-tritium (two isotopes of hydrogen) fuel. Our TSDS will store tritium in the form of uranium tritide and provide measured quantities of pure tritium gas to the reactor.

The approximately $\$ 800,000$ project will involve design work in conjunction with Ebasco/Grumman, the architectural-engineering firm responsible for overall reactor design. We will construct the TSDS, run full-scale tests with tritium before delivery, and train several Princeton technicians in tritium handling procedures.

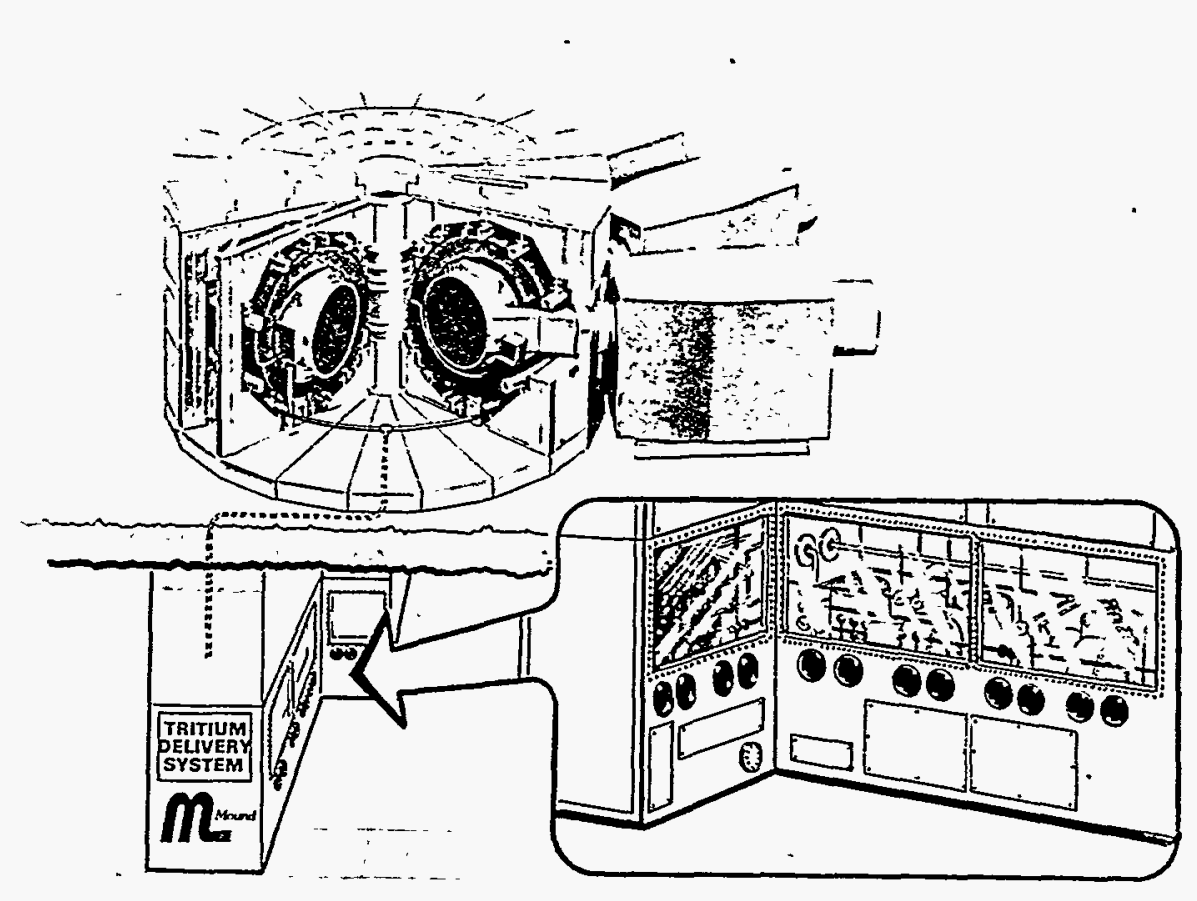

Mound's Tritium Storage and Delivery System will be located in gloveboxes a floor below Princeton's Tokamak fusion reactor.

Because tritium is radioactive, all handling operations will be performed safely within a closed glovebox system controlled from a remote location.

Mound participated in another fusion project during 1978: the Omega laser fusion program of the University of Rochester. We were selected to load a batch of glass microballoons, the fuel form for the reactor, with a deuterium-tritium mixture at 20 atmospheres of pressure. The $0.004-$ inch diameter microballoons are so small that Mound's first batch of 100,000 arrived in a $1 / 8$-inch diameter vial no more than $1 / 2$-inch long. The Rochester reactor, when completed, will use a brief, 0.05 to 1 nanosecond, pulse from 24 laser beams to initiate fusion in the microballoons. We will complete a series of loadings for Rochester at 10,20, 30,40 and 50 atmospheres pressure. 


\section{Energy Conservation}

Our Energy Conservation Program chalked up another year of positive results. Energy usage in 1978 was 6.3 percent less than the preceding year, and 8.5 percent less than the base year, 1975. DOE goal for the Facility is a 20 percent reduction by 1985 . In the Monsanto Energy Conservation Program begun in 1973, we surpassed the corporate goal of a 25 percent reduction by the end of 1977 , and estimate that by 1980 , we will show a 33 percent drop in energy consumption compared to the 1973 baseline.

The Energy Monitoring and Control System developed by our Engineering Department is scheduled for completion in 1983. The system includes a central computer and remote alarm and control units allowing optimization of building heating controls, automatic start and stop of equipment, chiller (air conditioning) loading optimization, selective measurement of electricity consumption, demand control, and boiler monitoring. Expected to pay for itself in less than five years, the system will save 2,554 MW hr. of electricity and 210,743 gallons of fuel oil per year.

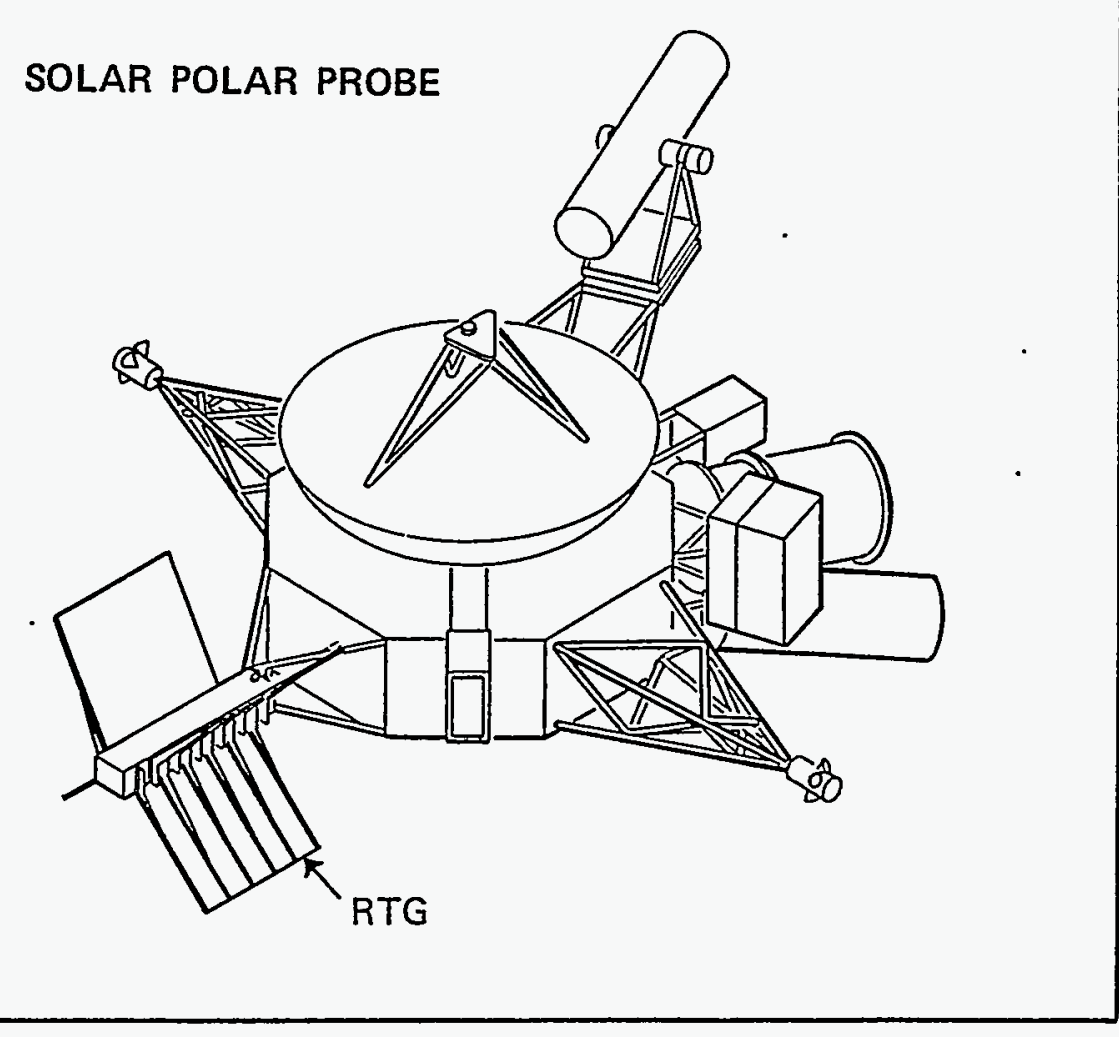

\section{Radioisotope Power Sources}

In the fall of 1978 , we received the contract for assembling and testing complete Radioisotope Thermoelectric Generator (RTG) units for a probe that will provide man with his first look at the polar regions of the sun. The 13-foot diameter solar polar probe will be powered by a large RTG rather than by solar cells because the mission orbit will keep the craft about as far from the sun as Jupiter. This large orbit is necessary because the probe, to be launched in early 1983 by the Space Shuttle, will make use of Jupiter's gravitational field to place it in an orbit perpendicular to that of the planets. It will be late 1988 before the probe will be over the pole of the sun. 


\section{Radioisotopes}

\section{Radioisotope Power Sources (cont.)}

Mound will make four RTG units, two to be used in two solar polar vehicles. The 4,500 thermal watt RTG's - the largest Mound has ever built - will be fueled by approximately 25 pounds of plutonium238 dioxide and will provide 300 watts of continuous electrical power for many years.

Approximately $\$ 1.6$ million was requested for expansion of existing facilities at Mound to accommodate the Solar Polar program. The program represents the first time we have had complete assembly and performance testing responsibility for such a power source.

We also assumed the role of heat source subsystem contractor in two other programs: The Galileo Mission and the In-Situ Heat Transfer Experiment. Mound will be responsible for reentry graphites, cladding materials, and final heat source assembly.

The Galileo Mission will use both an orbiter and an atmosphere probe for an extended look at Jupiter in the early 1980's. Galileo is slated to be the first interplanetary spacecraft launched by the Space Shuttle.

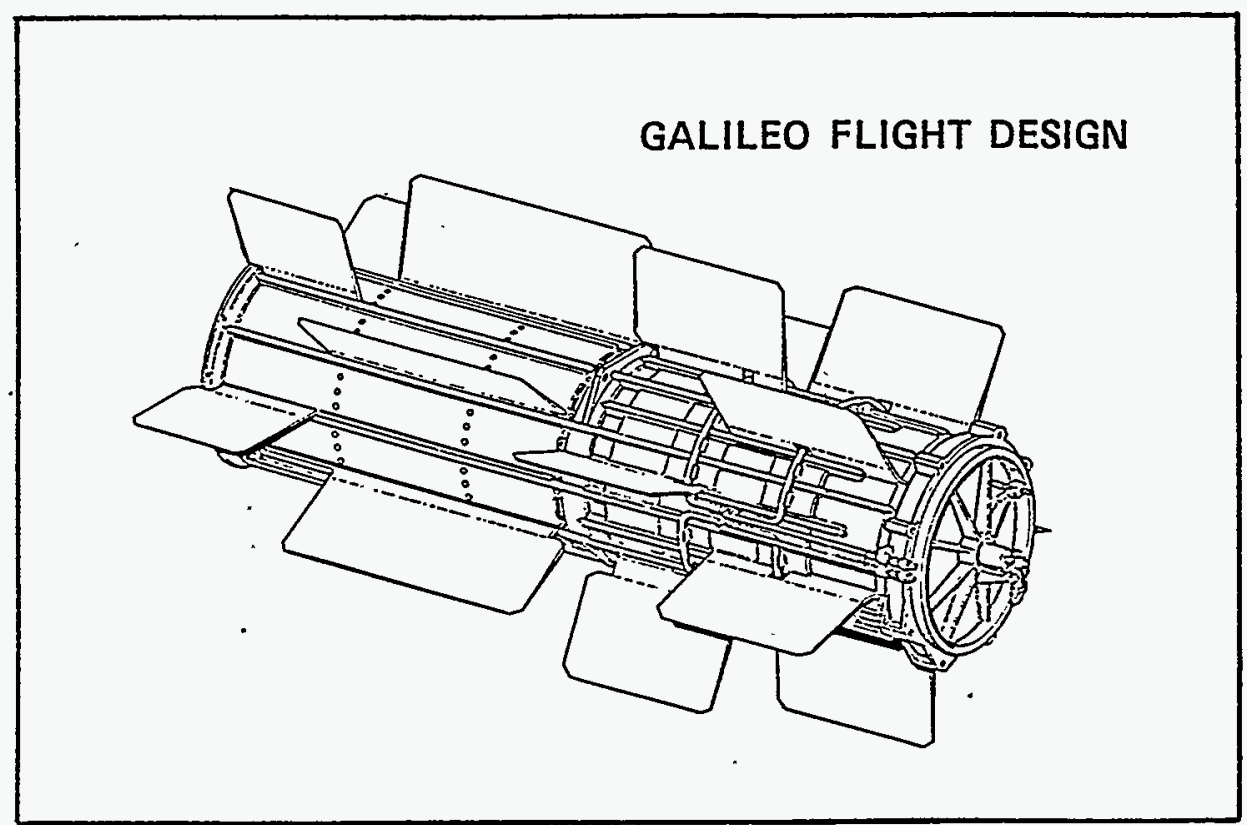

The In-Situ Heat Transfer Experiment will use a heat source to measure the thermal conductivity of ocean sediment. The heat source will be buried at a selected spot on the ocean floor 20,000 feet below sea level. Information obtained from this experiment will be used to determine the feasibility of ocean floor burial of radioactive waste.
Heat source developments during 1978 included the fabrication of two new powder metal frit vents, and advancements in warm forming shapes of brittle iridium alloy for plutonium containment. Frit vents are needed in heat sources to permit escape of helium generated by the plutonium fuel. One of the vents fabricated consisted of iridium powder sintered and diffusion bonded between iridium alloy foils; the other was a platinum, rhenium, and tungsten alloy powder pressed into a pellet which will be electron beam welded into the end cap of a heat source. 


\section{Nuclear Waste Technology}

Our role as a leader in radioactive waste treatment technology was enhanced in 1978 by further developments in waste immobilization, cyclone incinerator design, and liquid waste stream treatment.

For the first time, the Nuclear Waste Technology group at Mound demonstrated effective immobilization of radioactive incinerator ash in a pilot plant-mode operation. In-line testing verified that the past laboratory success with ash-cement mixture pellets could be repeated on a larger production scale. Preliminary product acceptance guidelines developed for the immobilizing matrix satisfy current DOE criteria for this form of radioactive waste isolation.

Modifications to our cyclone incinerator, such as special off-gas cleaning equipment now under development, will make it attractive to commercial nuclear power plants. In its present form, the cyclone incinerator has burned more than nine tons of radioactively contaminated solid waste. Work in progress on a combined liquids and solids incinerator will result in a full-scale system for the Fuel Materials Evaluation Facility of the Hanford Engineering Development Laboratory by the mid-1980's.

Ultrafiltration and reverse osmosis have shown promise as effective methods for treatment of radioactive liquid waste. Ultrafiltration

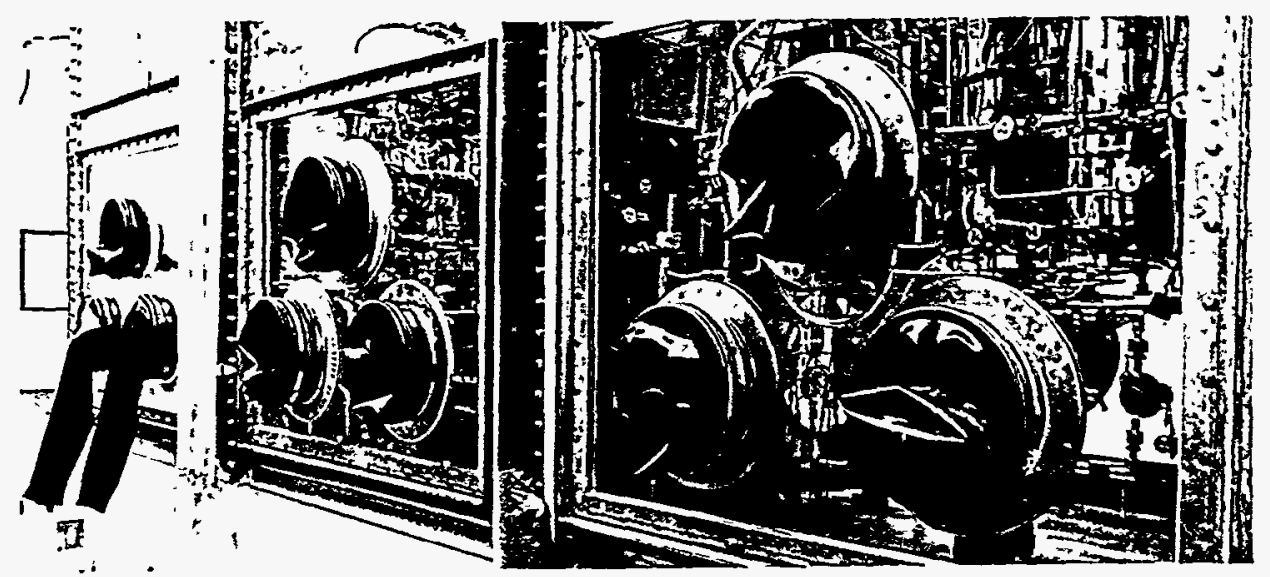

Carefully sealed and monitored gloveboxes such as this one in $R$ Building are used to contain tritium waste recovery operations.

membranes at Mound removed the major portion of radioactive contamination from all waste streams tested and have withstood alpha particle irradiation for $1 \frac{1}{2}$ years without degradation.

Reverse osmosis, which works especially well with ionic contaminants, removed a variety of actinides (a series of radioactive elements) from liquid streams initially treated by ultrafiltration. Work has started on a combined filtration-osmosis system that will decontaminate solutions containing both ionic and nonionic species.

Another way to decontaminate liquid radioactive waste streams is by means of an adsorbent. Our research in 1978 turned up several materials that draw radionuclides out of solution under various conditions, and a best all-around adsorbent, bone char, was demonstrated. Further work with inorganic adsorbents in the titanate and vanadate families should result in design criteria for a decontamination system that will accommodate a commercial nuclear fuel cycle waste stream.

Tritium, a radioactive isotope of hydrogen, is particularly difficult to remove from waste because it behaves chemically in a manner similar to the common hydrogen that makes up water. Ordinary chemical methods, therefore, are not effective at separating tritium from aqueous waste. Mound work in this area indicates that molecular photoexcitation may be the answer. Experiments have shown that ultraviolet and infrared lasers can be used to dissociate gaseous water molecules and separate the more massive tritium atoms from ordinary hydrogen. 


\section{Separations Technology}

\section{Stable Isotopes}

Mound is one of the world's largest producers of stable isotopes - specializing in stable forms of the noble gases, chlorine, bromine, and in the life science isotopes of carbon, oxygen, nitrogen, and sulfur. In 1978, advancements in separations technology resulted in a substantial reduction of the price of carbon-13 at 99 percent enrichment and made it possible to offer this scarce isotope in the form of carbon monoxide for the first time.

Isotopes have a wide variety of applications, the most noteworthy occur in medical, agricultural, and biological research. Isotopes of nitrogen are helping scientists evaluate the many factors that affect the growth of food crops. Reasons for toxic effects of various chemicals on animals and man can be tracked down by

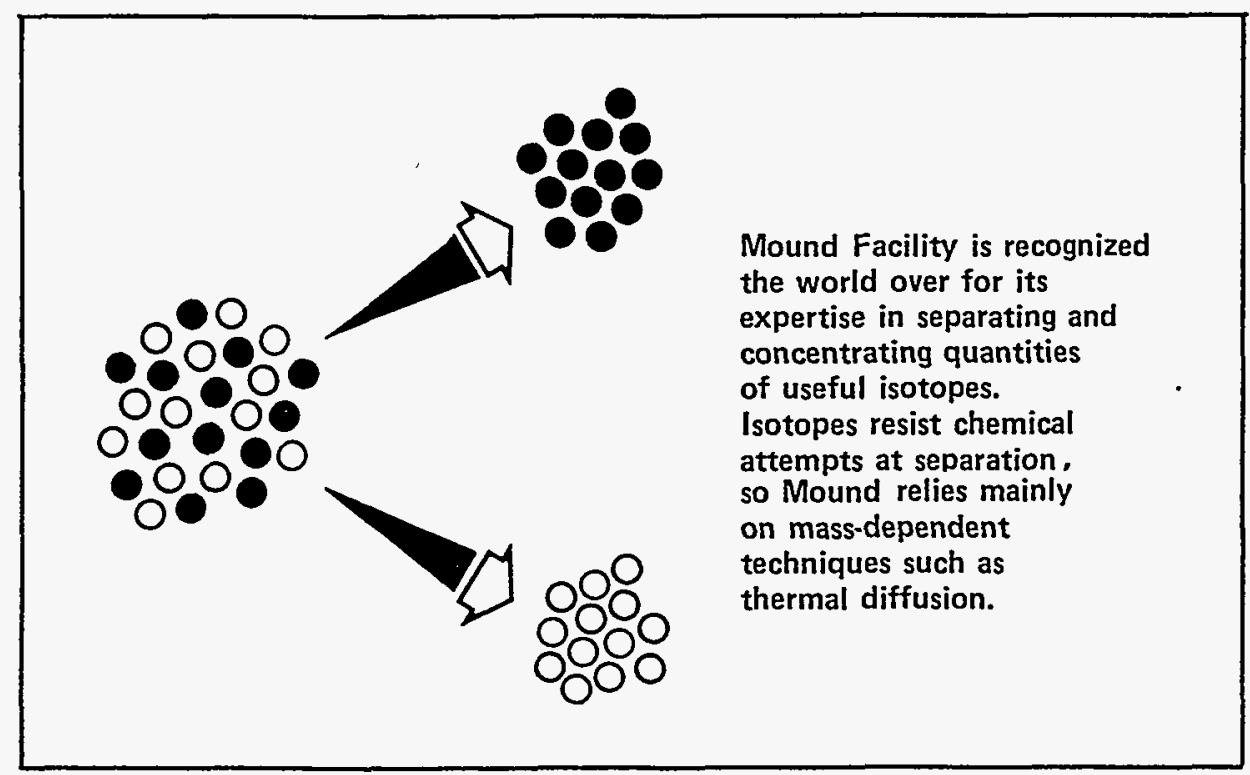

"tagging" the suspect compounds with isotopes. Potential uses of isotopes for the early detection of pulmonary, liver, and blood disorders as well as cancer and diabetes are just now being realized. Stable isotopes have an important role in the study of human and animal metabolism, as well as in oil exploration, nuclear fuel element gas tagging, geological dating, pollution detection, low-temperature research, and other areas.

A separation method for scarce stable metal isotopes is under development at Mound. Applications of enriched metal isotopesin the nuclear power industry, biomedical research, and clinical medicine may expand if this work results in reduced enrichment costs.

\section{ENRICHMENT OF SCARCE ISOTOPES PRODUCED AT MOUND IN 1978}

\section{Enrichment}

\begin{tabular}{cll} 
(\%) & Isotope & \\
\hline 99.9 & Helium-3 & \\
99.95 & Neon-20 & \\
90 & Neon-21 & \\
$70,99.9$ & Neon-22 & \\
99.5 & Argon-36 & \\
$8^{*}$ & Argon-38 & \\
90 & Krypton-80 & \\
70 & Krypton-86 \\
$5,20,40$ & Xenon-124 & \\
2 & Xenon-126 \\
80 & Xenon-136 \\
99 & Carbon-13 & \\
& &
\end{tabular}

* For subsequent enrichment to more than $95 \%$. 


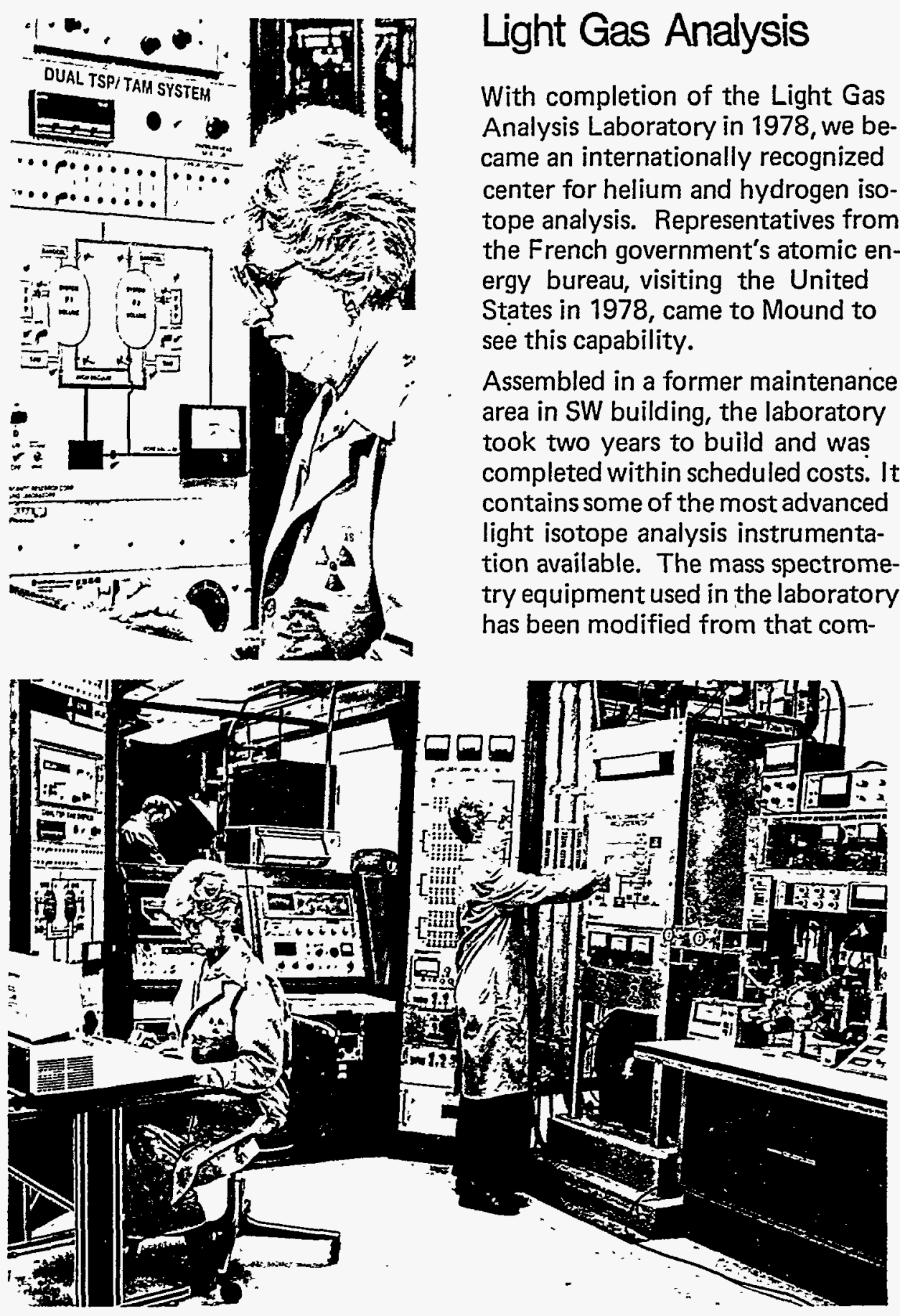

Marilyn Garrod (above) feeds information into the computerized Light Gas Analysis Laboratory. It takes three technicians (below) about 15 minutes to analyze a sample in the new lab. Shown are Marilyn Garrod (left), Judy Blanton, and DeWayne Spadafora (background). mercially available to suit Mound's needs in the 2-6 atomic mass unit range. The instrument used to measure total inert gas and tritium content of samples - the titanium sublimation pump/tritium analysis meter - is Mound-built and does not exist in this form anywhere else in the world.

Samples of gas from several locations throughout the building are conveyed directly to the laboratory by capillary tubes - a system that minimizes the risk of a tritium release. Total containment of the gas sampling system and vacuum pumps, along with a special tritium removal system for pump exhaust, protects both the environment and operating personnel from contamination. Remote control of the sampling process from a central location allows the analyses to be conducted by an operator in normal laboratory. clothing.

A typical isotopic and impurity analysis takes no longer than fifteen minutes from the time the sample is drawn to the print out of a computer report. High instrument accuracy is ensured by regular checks of the system with gas standards traceable to the National Bureau of Standards. 


\section{Explosives Technology}

\section{Advanced Devices}

A major Advanced Devices Department accomplishment in 1978 was the swift development of a new isolator, a weapon component. Normally a three-year effort, Mound broke records bringing this project from concept to production in a year's time.

Corrosion in an actuator that puzzled the DOE weapons complex found a solution at Mound. In conjunction with Sandia Laboratories, Albuquerque, our experienced Analytical Section focused its attention on the interaction of metals, solvents, and glues - and the offending agents were identified. The corrosion problem was corrected, and valuable information on longterm compatibility of materials was obtained for future applications.

A substantial portion of the cost of producing intricate high-quality components is the labor time needed to document the many operations performed on each part. Our new Computer Data Acquisition Control system, COMDAC, reduces this cost by automatically monitoring and recording production variables.

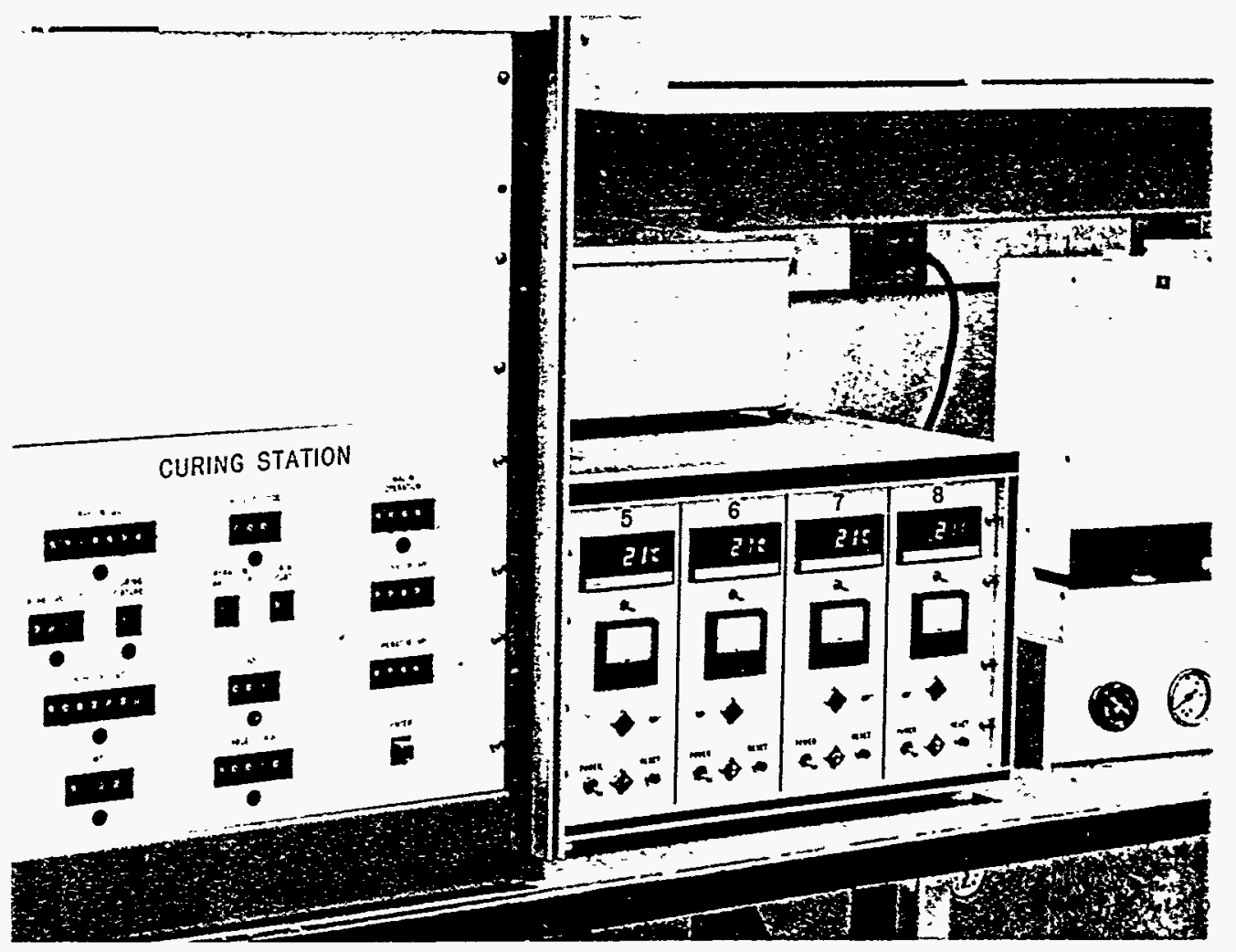

Kathleen Hitte places a detonator head cable assembly into a thermal curing press at one of monitored by Mound's COMDAC system.

COMDAC uses a centrally located computer to monitor eleven production locations in three buildings. Installed in 1978, it will begin managing crimping, welding, heating, and measurement operations in mid-1979. Because COMDAC is a real-time production data system, it can reduce rejects by notifying workers of discrepancies or deficiencies the moment they occur. All production data are stored and quickly accessible by video display terminal or printout - vastly simplifying assembly of detailed reports by the production engineer.
Improved accuracy and faster component processing is also available through another new Advanced Devices system. Surveillance, electrical testing, disassembly, and test fire data obtained for non-nuclear weapon components at many locations throughout Mound can now be immediately recorded and stored in a central computer data base. The new system provides an audit trail of the components as they move through the Facility. 


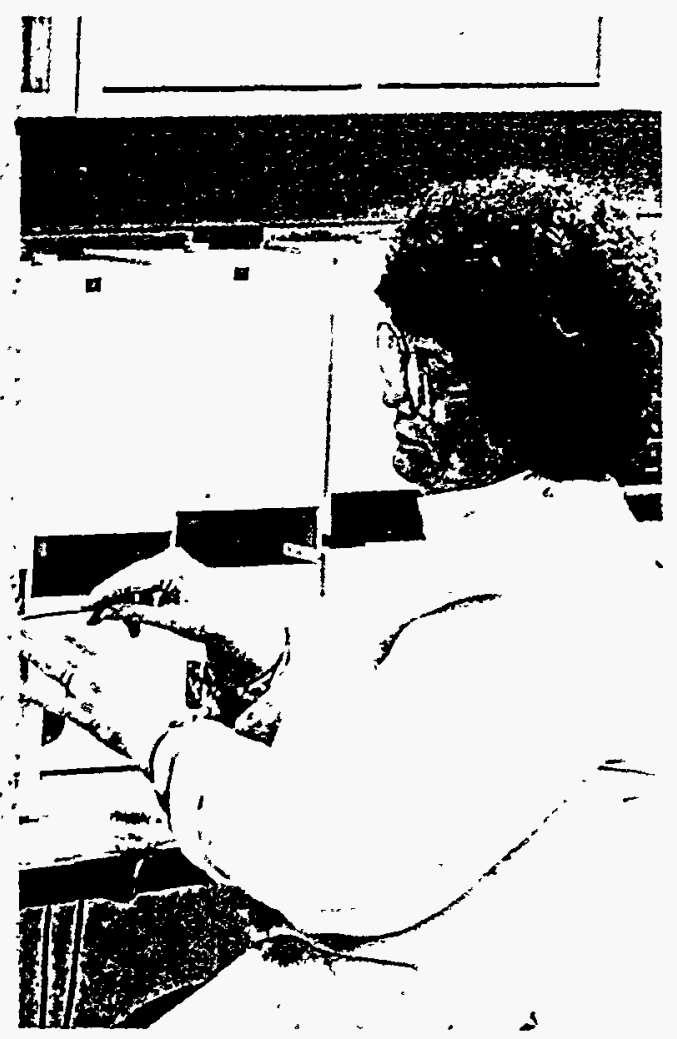

11 production stations automatically

\section{Nondestructive Testing}

Our Californium Multiplier (CFX) Neutron Radiography Facility completed its first year of operation in 1978, exceeding expectations with its production of quality radiographs.

Prior to installation of the CFX, all neutron radiographs were made offsite at the Argonne CP5 reactor limiting flexibility in this technique. Neutron radiography is important to many programs at Mound because of its fine resolution of hidden detail within sealed components.

To enhance radiation safety awareness in $\mathrm{X}$-radiography areas, the Nondestructive Evaluation group established a three-member internal safety committee. The committee surveys all $x$-ray areas twice yearly to ensure compliance with safety policies, and provides safety information to operating personnel. All $x$-ray manuals now include an equipment safety procedure.

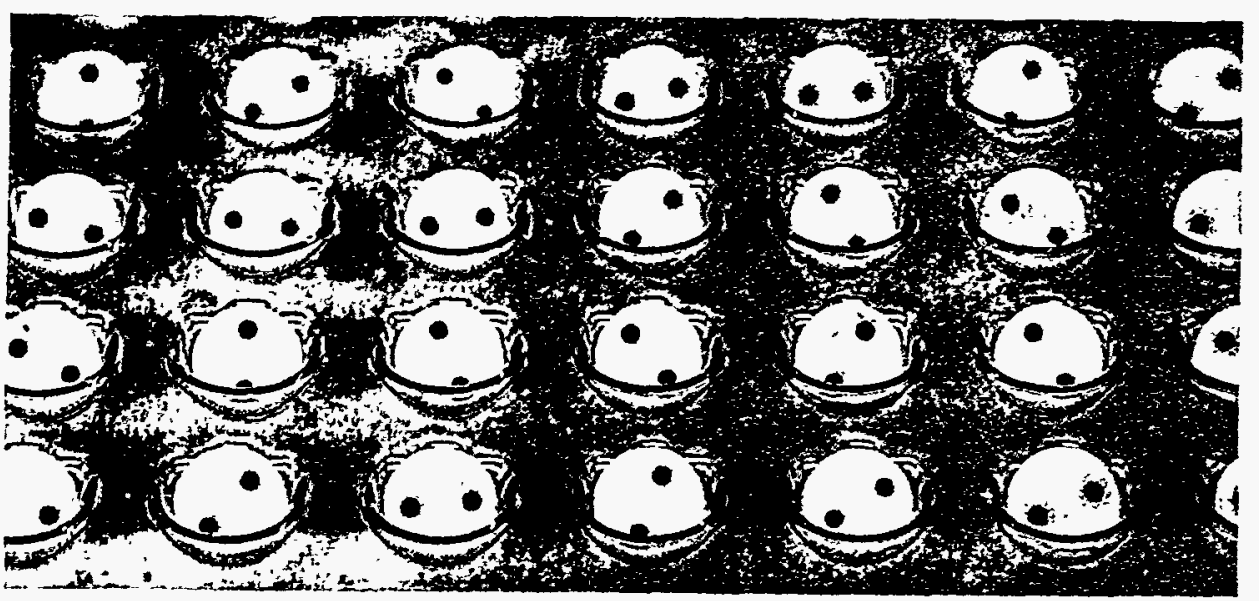

A tray of ceramic parts awaits inspection in the Advanced Devices ceramics laboratory.

To improve utilization of labor and reduce the cost of product testing, a technician training program in the areas of ultrasonic, eddy current, dye penetrant, and leak testing was established. This expanded training effort will eventually free the nondestructive evaluation engineer from routine testing responsibilities and enable him to concentrate on problems of a more complex nature. 


\section{Explosives Technology}

\section{Ceramics}

Expansion of our ceramics capability was accelerated in 1978 by the DOE assignment of all development and production responsibility for ceramics used in Mound-built actuators and detonators. This assignment includes both cermet (metallic ceramic) and glass ceramic activities previously handled by other DOE contractors. Design of a new 4,000 sq. $\mathrm{ft}$. two-story laboratory to handle our increased involvement in ceramics was completed in preparation for construction in early 1979.

Our ceramic operations involve four distinct areas: fabrication of small alumina bodies of complex configuration, ceramic-to-metal seals using both conventional and Mounddeveloped metallizing and brazing techniques, processing of ceramic substrates with integral cermet electrical pathways, and fabrication of components using glass-ceramic electrical insulators.

Alumina bodies are fabricated by a variety of conventional techniques, including slip-casting and extrusion

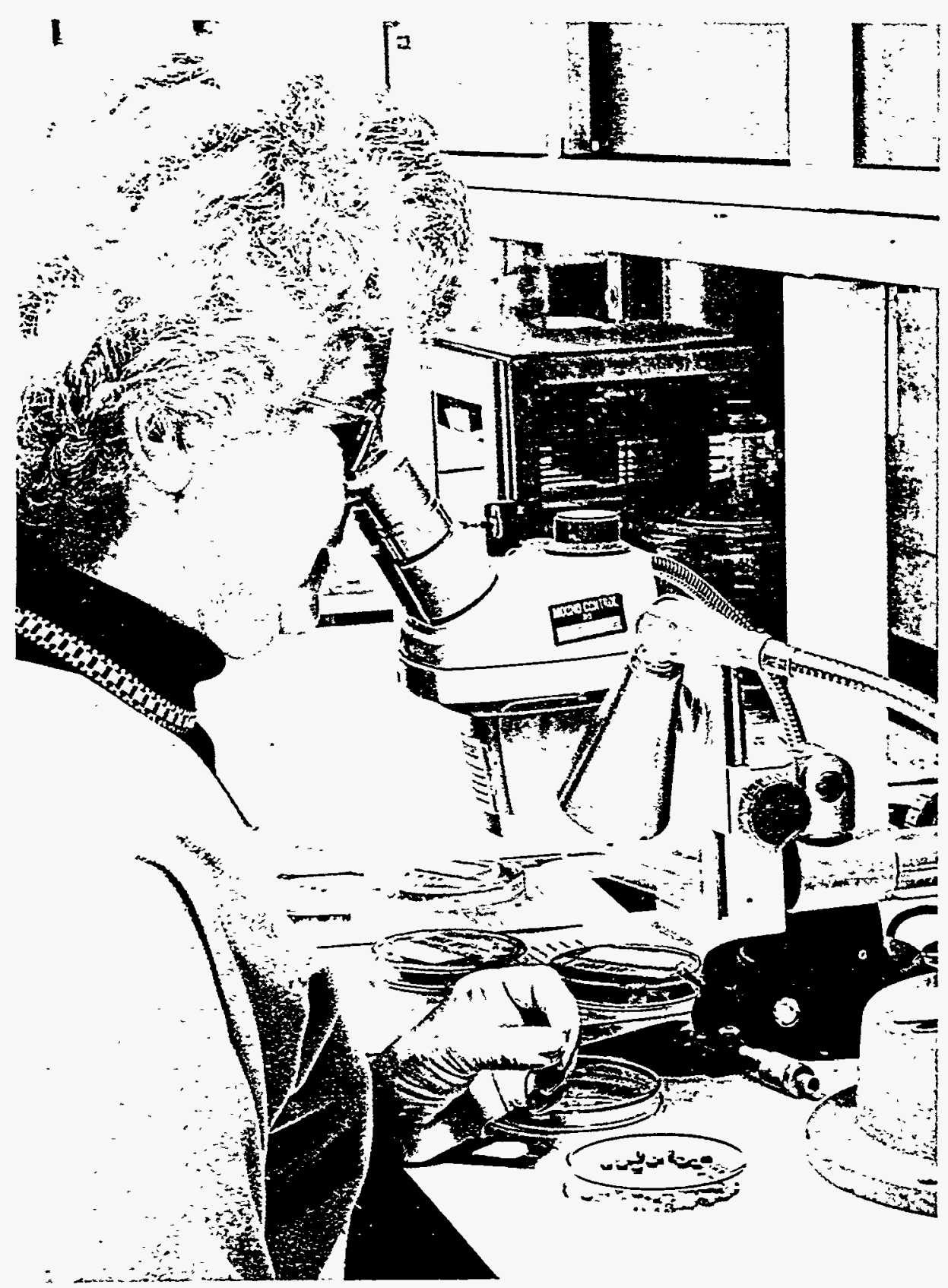

Della West closely examines small ceramic detonator parts with the aid of a stereoscopic microscope. 


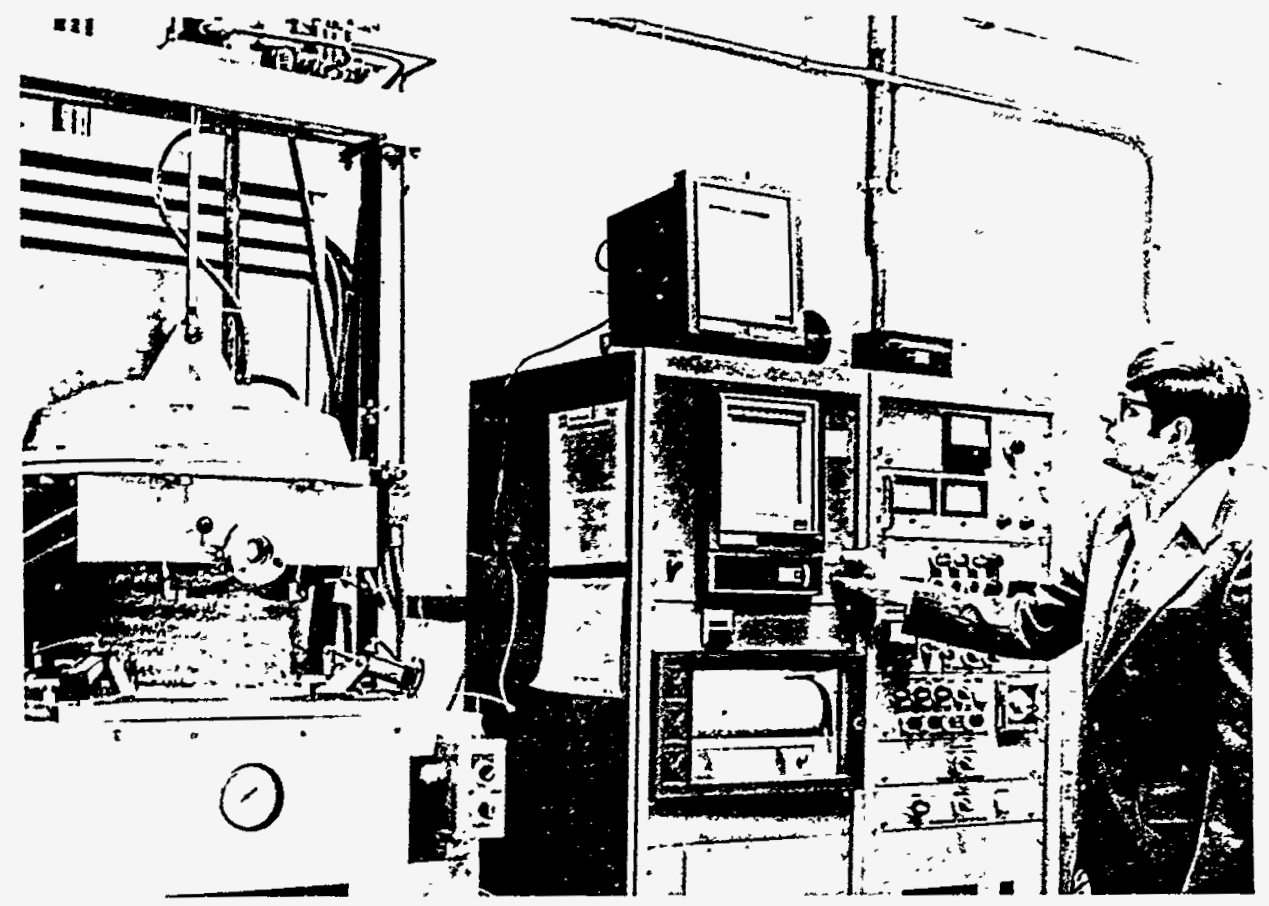

Paul Gray fine-tunes the programmer of a ceramic sintering furnace (left). The panel provides a continuous graph of furnace conditions including time, temperature, and pressure. The furnace can bring ceramic parts to $1800^{\circ} \mathrm{C}\left(3300^{\circ} \mathrm{F}\right)$ in vacuum, or in an argon or hydrogen atmosphere.

- and nonconventional methods such as the transfer and injection molding techniques developed at Mound for use on complex shapes.

Ceramic-to-metal seais are formed by metallizing the ceramic alumina body with a molybdenum-based metallizing agent. Molybdenum's thermal expansion characteristics closely match those of alumina, and the metal is usually applied by a paint-on, dip, or screen print process followed by exposure to high temperature. Development work on a solution-based metallizing process in 1978 has shown that this method can result in a more uniform coating in hard-to-reach small-diameter holes. Another advantage of the solution-based system is the relatively low firing temperature: $1100^{\circ} \mathrm{C}$ as compared to $1450^{\circ} \mathrm{C}$ for the other processes.
An alumina-molybdenum cermet electrical pathway through an alumina substrate provides an excellent base for one of our production specialties: metal vapor-deposited electrical circuits. Since both molybdenum and alumina grind and polish at the same rate, an extremely smooth surface can be achieved.

High thermal expansion glass ceramics offer great promise in both cost and technical versatility. Our work in this new technology during 1978 focused on casting processes to eliminate the expensive diamond grinding needed to shape conventional ceramics. Glass ceramics are useful as high-temperature insulating materials because they can be formulated to match the thermal expansion of adjoining metal parts. 


\section{Environment}

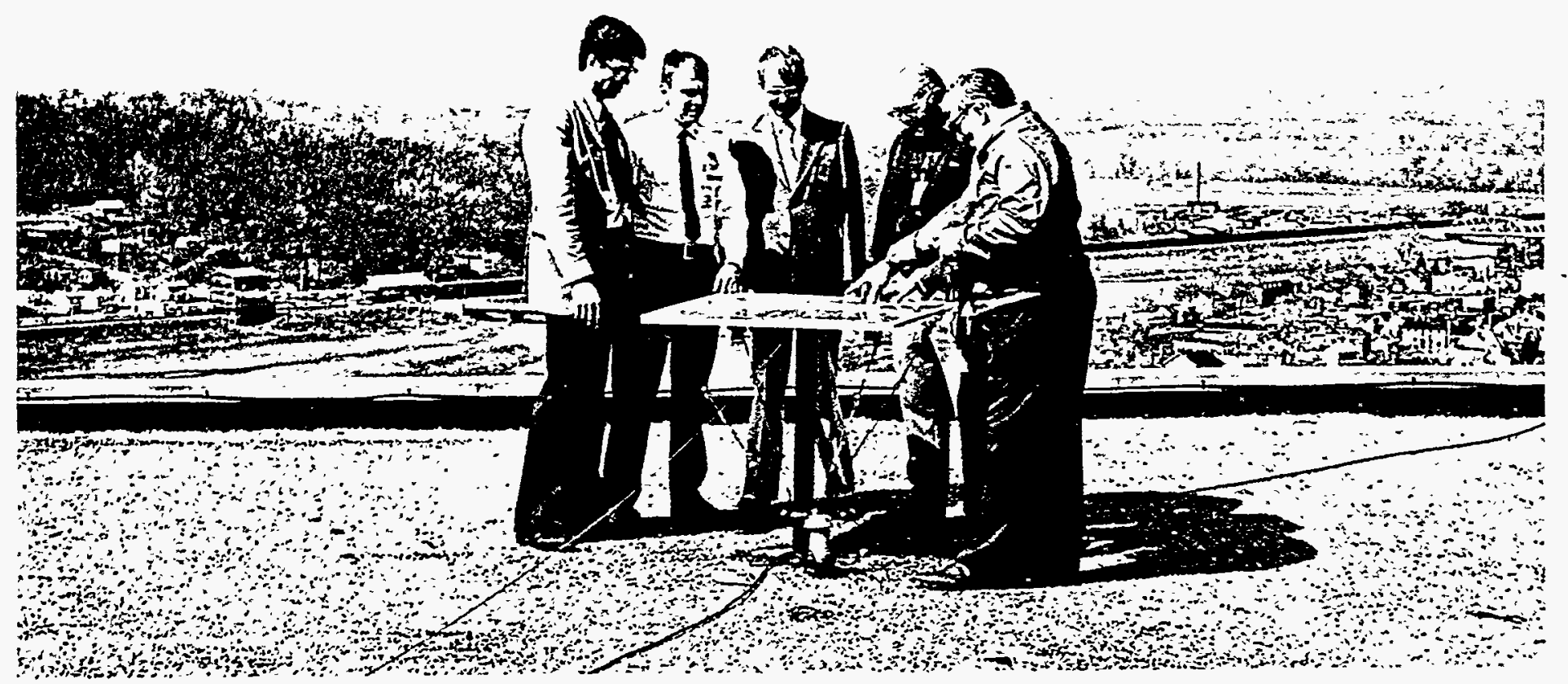

The roof of Mound's OS Building gives a panoramic view of the Miamisburg area, making it a perfect location for a tornado spotting station. Lane Metcalf (left), Miamisburg Firechief Norman Mason, Miamisburg Safety Director Ron McBride, Jeem Newland, and James Hall, examine the weatherproof map and sighting device installed by Mound to track potentially dangerous weather formations. The Miamisburg Amateur Radio Association, headed by Jeem Newland, maintains a radio network designed to assist local safety organizations during such emergencies.

\section{ARAC System}

A computer-telephone weather data linkup completed last year now enables Mound personnel to calculate which way and how fast airborne hazardous materials might spread after a chemical release accident anywhere in the Miamisburg area.
Our Atmospheric Release Advisory Capability (ARAC) system is connected via telephone lines to the ARAC central facility of the Department of Energy's Lawrence Livermore Laboratory (LLL). Through LLL, we are able to obtain information on regional weather conditions to complement local Mound-gathered meteorological data. Our own computer produces a revised area dispersion plot from local information every fifteen minutes.
The computer program models used range from simple Gaussian to complex regional transport models which take terrain into account. The more complex models require use of LLL's CDC 7600 computers. Our ARAC facility consists of a DEC PDP-11 mini-computer with video display terminal, printer, and teletype output. Data are transmitted to LLL every four hours and regional calculations are communicated back to Mound through the telephone link when required. 


\section{Environmental Technology}

Mound completed two collaborative studies for the EPA in 1978, aimed at developing analytical methods for the determination of uranium in environmental samples. "Uranium in Water" and "Uranium in Soil and Air" were written for publication as EPA reports.

Burning coal in a conventional manner releases small quantities of radioactive elements found naturally in coal deposits. In 1976, the Environmental Protection Agency initiated a program at Mound to study poten- tial environmental impact of these radionuclides.

Phase I, completed in 1978 under the Department of Energy, surveyed the pathways of radionuclides in the coal fuel cycle. Research indicated that a modern power plant burning Western coal adds a negligible amount of radioactive material to the environment through stack emissions - anywhere from 0.1 to 1.0 percent of background radiation. Phase I work revealed that most of the radionuclides found in coal accumulate in ash ponds or piles after burning. Phase 11 , begun in 1978 , involves studying the partitioning of radionuclides from feed coal to ash and sludge, as well as the migra-

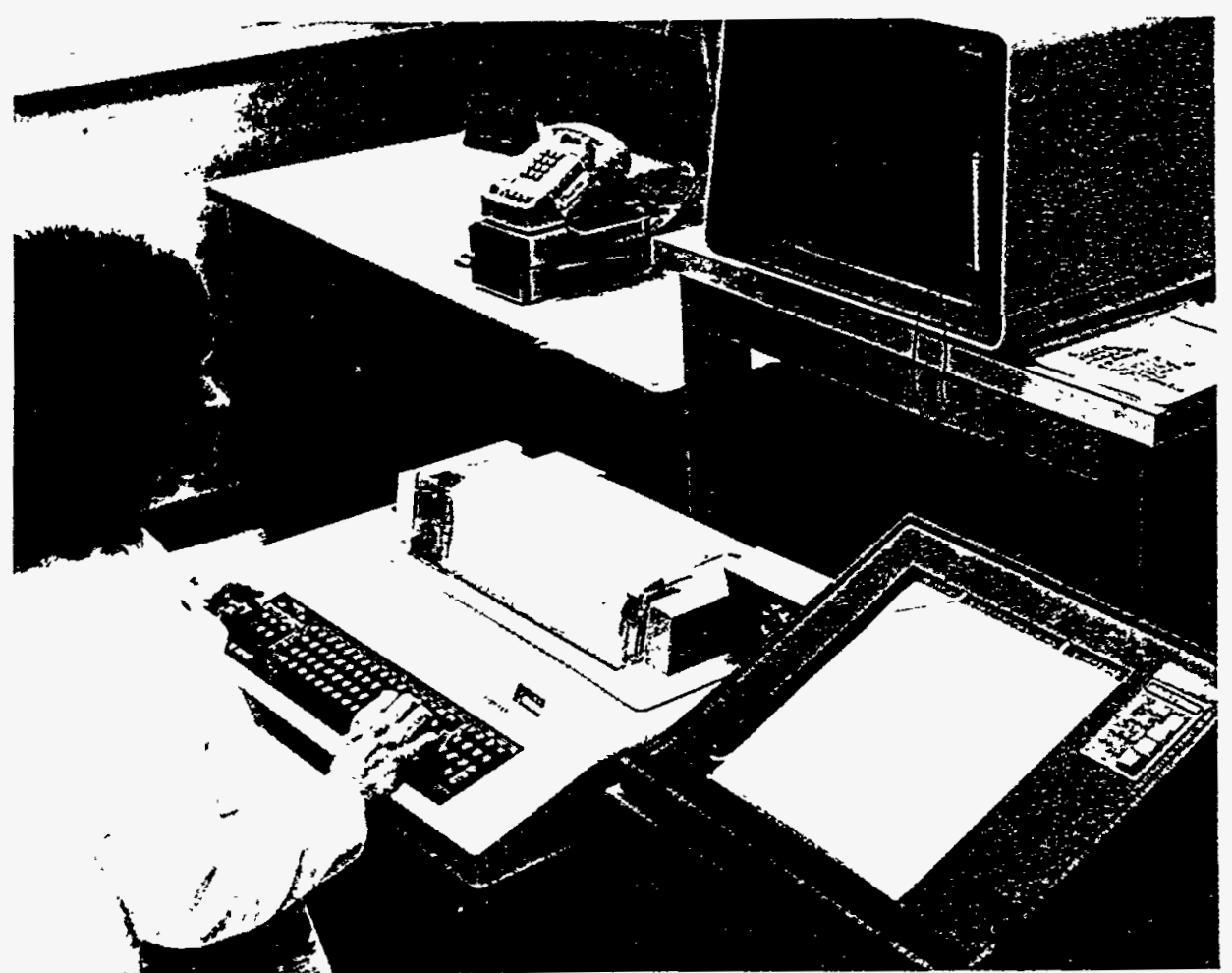

The ARAC terminal at Mound, operated here by Patricia Wright, provides access to regional weather information from Lawrence Livermore Laboratory and can plot wind dispersion diagrams from local Mound-gathered weather data.

tion of radionuclides (particularly radon-222) from refuse disposal sites.

To determine the local environmental effect of our own activities, a plutonium-238 soil inventory for the area around and within the boundaries of the Facility was completed in 1978. Background soil samples were compared to nearby soil core values to determine the amount of plutonium-238 deposited in the environment from Mound stack emission. The results show that our impact on soil concentrations in the offsite environment is well within the proposed EPA standard for transuranium elements in soil. 


\section{People}

\section{Family Day}

Smiling youngsters gripped key chains freshly engraved by a laser beam and intently watched their temperature displayed in glowing digits at the touch of a thermocouple. Kids of all ages sat at blinking video screens, touching buttons and playing games with a computer not easily beaten. A young lady, holding a red carnation, was guided "switch by valve" through the operations used to move tritium through a glovebox. Employes, their families, and guests experienced the many aspects of Mound Facility on Sunday, October 8,1978 , during a three-hour tour and family day commemorating our 30th anniversary.

Exhibits in 62 display areas, featuring all the varied areas of research at Mound, were viewed by 809 employes and their 2,370 guests during this sunny fall afternoon.

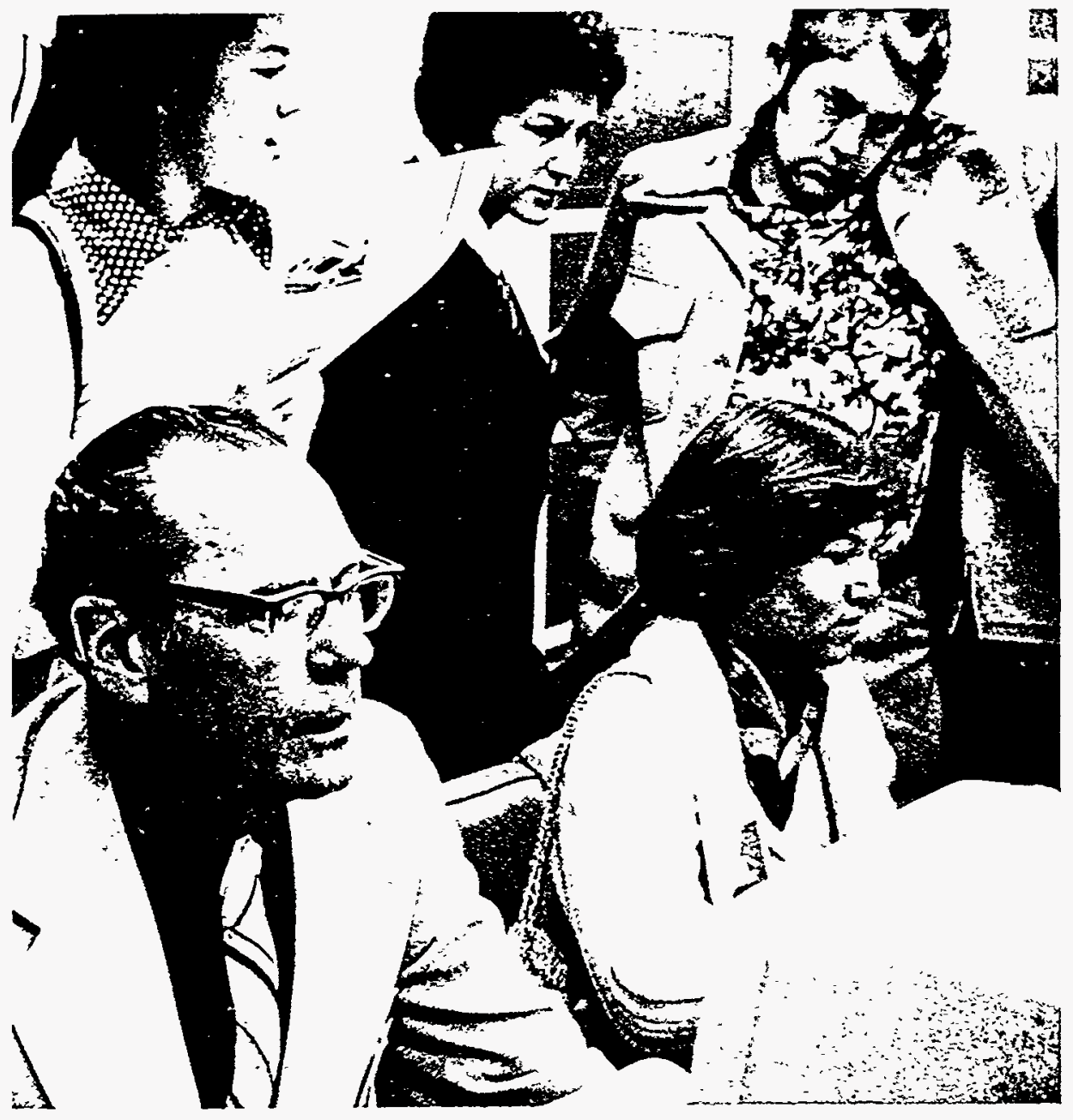

The Data Processing Section's computer technology presented no age barriers as far as Family Day visitors were concerned. A large majority of the nearly 3,200 sightseers had a chance to sit at video display terminals and converse with the computer. 


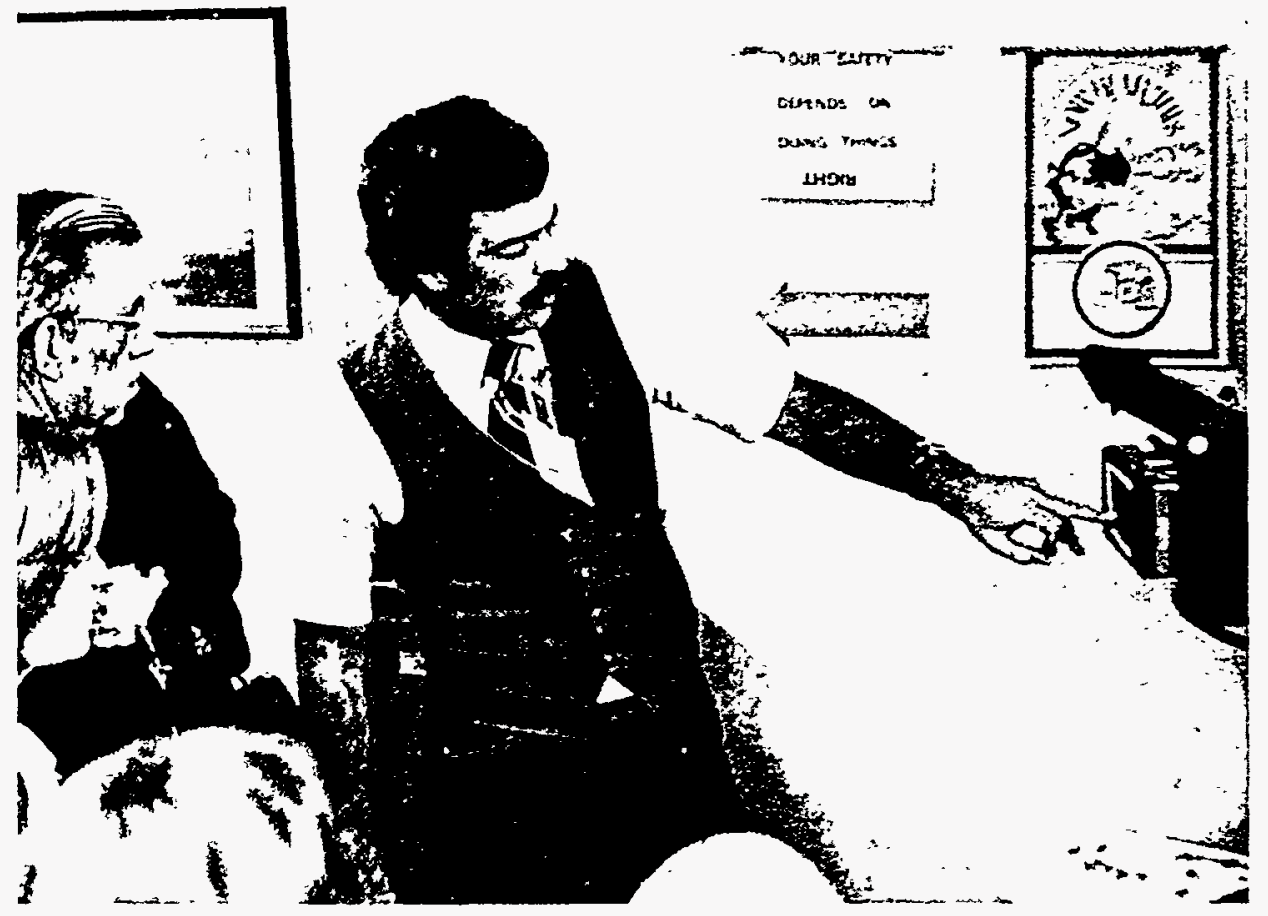

Translating technology for a fascinated audience, Terry Ferguson explains the role of a film holder on a detonator testing device. Photographic records of oscilloscope traces are important documentation for detonator tests.

\section{Communications}

During 1978, sixteen major stories about Mound appeared in the local news media. The diverse range of topics included: Monsanto involvement in the Miamisburg solar pond, Mound security, the stabilization of plutonium in the Miami-Erie Canal, the Mound Open House, Decommissioning of the Plutonium Processing Building, and Mound commentary on the reentry of a Russian nuclearpowered satellite. In addition, two Mound scientists participated in a radio talk show about energy.
Our scientists communicated Mound's technological achievements through 200 publications and presentations in 1978. More than 90 of these were oral presentations given before major Department of Energy groups and professional societies. Forty-five topical reports 8 to 88 pages in length were published and made available to the scientific community, as were 39 technical progress reports and 11 journal articles. Five special publications completed during the year put forward Mound's accomplishments in nontechnical terms for the general public.
In keeping with our efforts to maintain a dialogue with news organizations, we held a fall dinner for the local news media. The multimedia program was an update of our activities related to development in energy research such as Devonian gas shale assessment and in-situ coal gasification.

Mound took its operations story to Monsanto with a 35-minute sound and slide presentation for the company's Corporate Administrative Committee. The presentation, which will also be used as an introduction for our visitors, detailed the Facility's technological efforts and related those efforts to developments in the commercial world.

The Mound Speakers' Bureau, whose members gave 11 presentations during 1978, was restructured to include 12 other Monsanto Ohio plants and locations. A training session in the fall for members of the new Speakers' Bureau was held to dovetail efforts with Monsanto's Chemical Facts of Life Bureau. Fifteen of the more than 30 speakers available for chemical and scientific programs throughout Ohio are Mound employes. 


\section{People}

\section{Safety}

Safety in the handling of explosive and chemically unstable materials at Mound received a boost with the establishment of the new Energetic Materials Safety Review Committee (EMSRC) and a Pyrotechnic Safety Project.

The seven-person EMSRC replaced the Pyrotechnic Safety Review Committee and provides technical guidance for safety in all operations involving primary and secondary explosives, pyrotechnics, thermites, heat powders, and other energetic materials. The committee has responsibility to review and approve both new and current procedures involving energetic materials.

Safety technology in general reference form is the goal of the Pyrotechnic Safety Project. A manual on pyrotechnic safety will be compiled for use throughout the DOE complex.

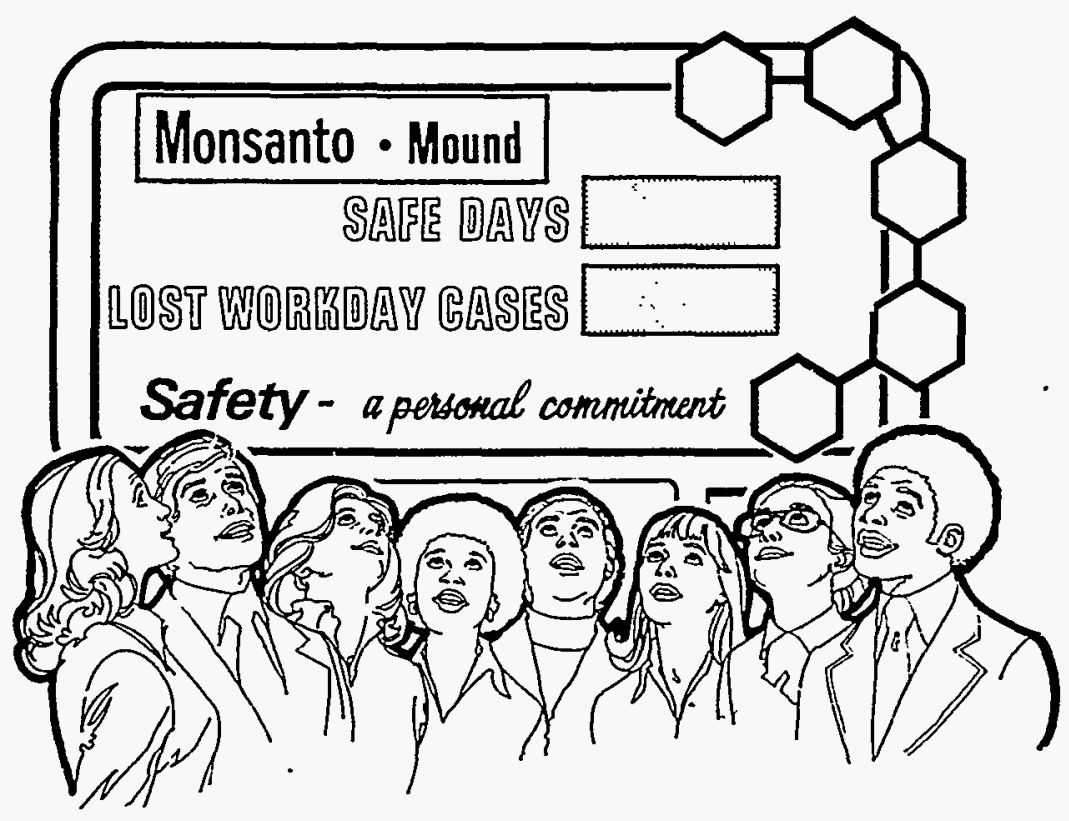

Overall, our OSHA-recordable injuries and illnesses for 1978 were fourteen and two, respectively. Two of these injuries were falls caused by icy winter conditions. This was the first year Mound applied the OSHA system for reporting accidents.

In the radiological safety area, there were no major incidents in 1978. Minor radiological incidents and unusual occurrences totalled 25, down from 28 in 1977. Our emphasis on keeping employe radiation exposures as low as practicable (ALAP) was reflected in the absence of whole body radiation exposures exceeding 2.0 rem for 1978 -a 20-year low. This dosage represents 40 percent of the DOE annual standard and exceeds outstanding radiological health goal criteria approved for 1978 by the Mound Executive Safety Committee. Corporate Monsanto received the benefit of our expertise in respirator use and radiation safety in 1978 when the Safety and Environmental Technology Section made respirator fitting and testing information available to other company locations.

Mound was visited by an editor from the Dayton Daily News and a news producer from WHIO-TV, who briefed the Emergency Team on the needs of the media during an emergency. Carl Nichols, WDTN-TV 


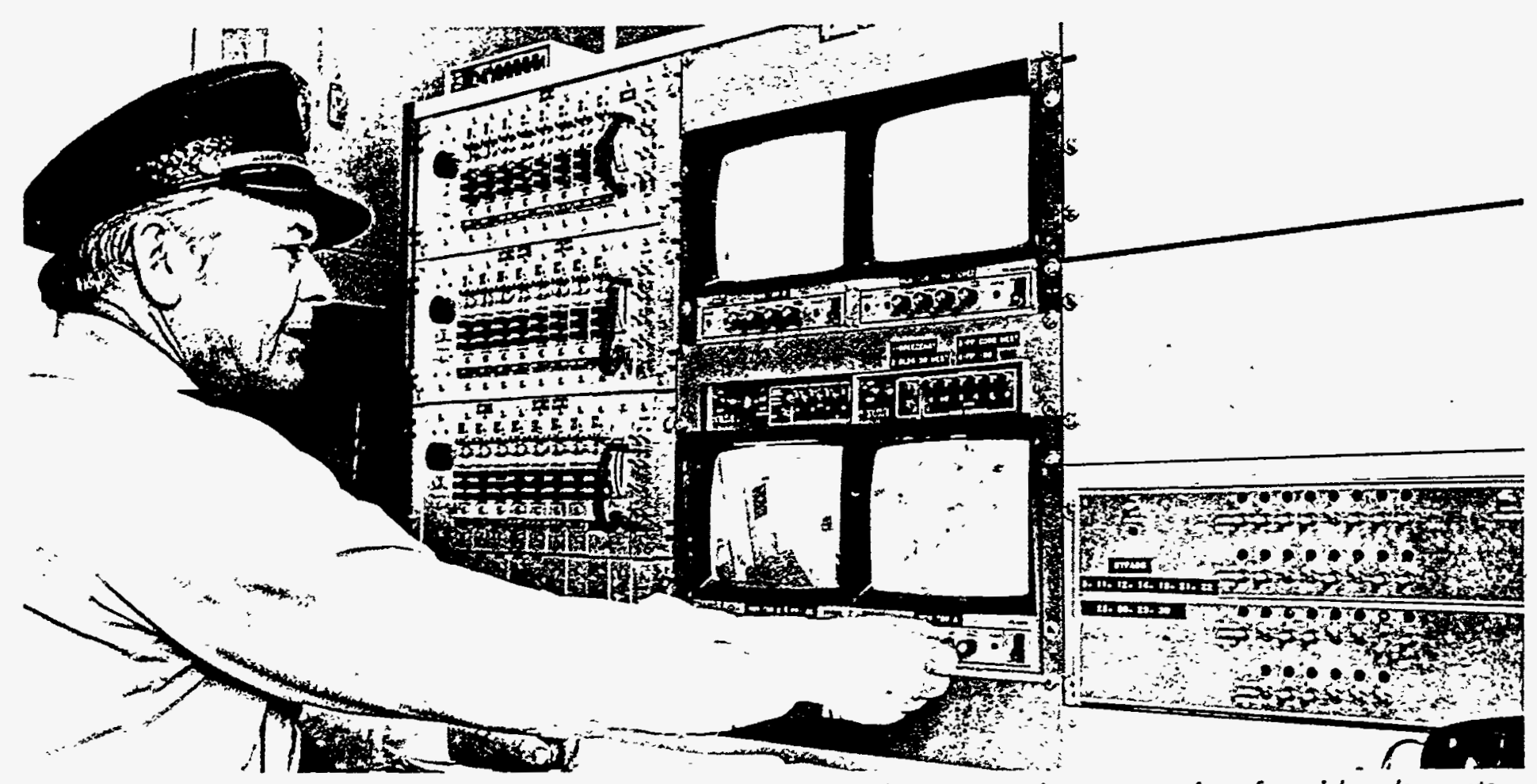

Guard John Holbrook adjusts a video monitor in the new security system designed to enhance protection of special nuclear materials at Mound.

meteorologist, held safety meetings for Mound employees on severe weather safety measures. The active Safety Education Committee sponsored programs on defensive driving and on the hazards of smoking, as well as a diet workshop. Because of its popularity, the diet workshop became a weekly course on weight watching and nutrition attended by thirty employes.

A computer system to maintain and report chemical handling data was developed for the Industrial Hygiene Group. The system keeps up-to-date information on approximately 600 chemicals in use here as well as the personnel who handle them.

\section{Security}

Enhanced protection of special nuclear materials at Mound was ensured with the completion of a new $\$ 245,000$ monitoring system and a thorough security study in 1978.

Closed-circuit TV cameras and special. sensors throughout the plutoniumprocessing area are now monitored around the clock at a central control area. The System Analysis Study undertaken in 1978 will also result in improved special nuclear material security.
Four security infractions occurred in 1978, one less than the previous year. The three-year security reorientation required by DOE was completed for all Mound employes during the spring. 


\section{People}

\section{Community Affairs}

We took an active interest in the surrounding communities in many ways during 1978. Financially, the area benefitted from our payroll of nearly $\$ 32$ million and our small business orders totalling $\$ 9.5$ million in 1978 , including $\$ 545,000$ in minority business expenditures. Extension of blanket orders gave Mound more opportunities than ever to do business with small and minority suppliers.

A luncheon for local black community ministers given by Mound and Monsanto Research Corporation's Dayton Laboratory resulted in agreements permitting employe recruitment through churches in minority areas. The Selection and Placement Office now regularly distributes recruitment posters to the black community.

We were a leading contributor to the establishment of the Miami Valley Equal Opportunity Coordinators Council in 1978. The Miamisburg Market Square Association also benefitted from Mound expertise when it received help in the recruitment of a part-time Economic Director.

An art contest for local public school students co-sponsored by Mound and the Miamisburg News attracted more than 500 entrants.

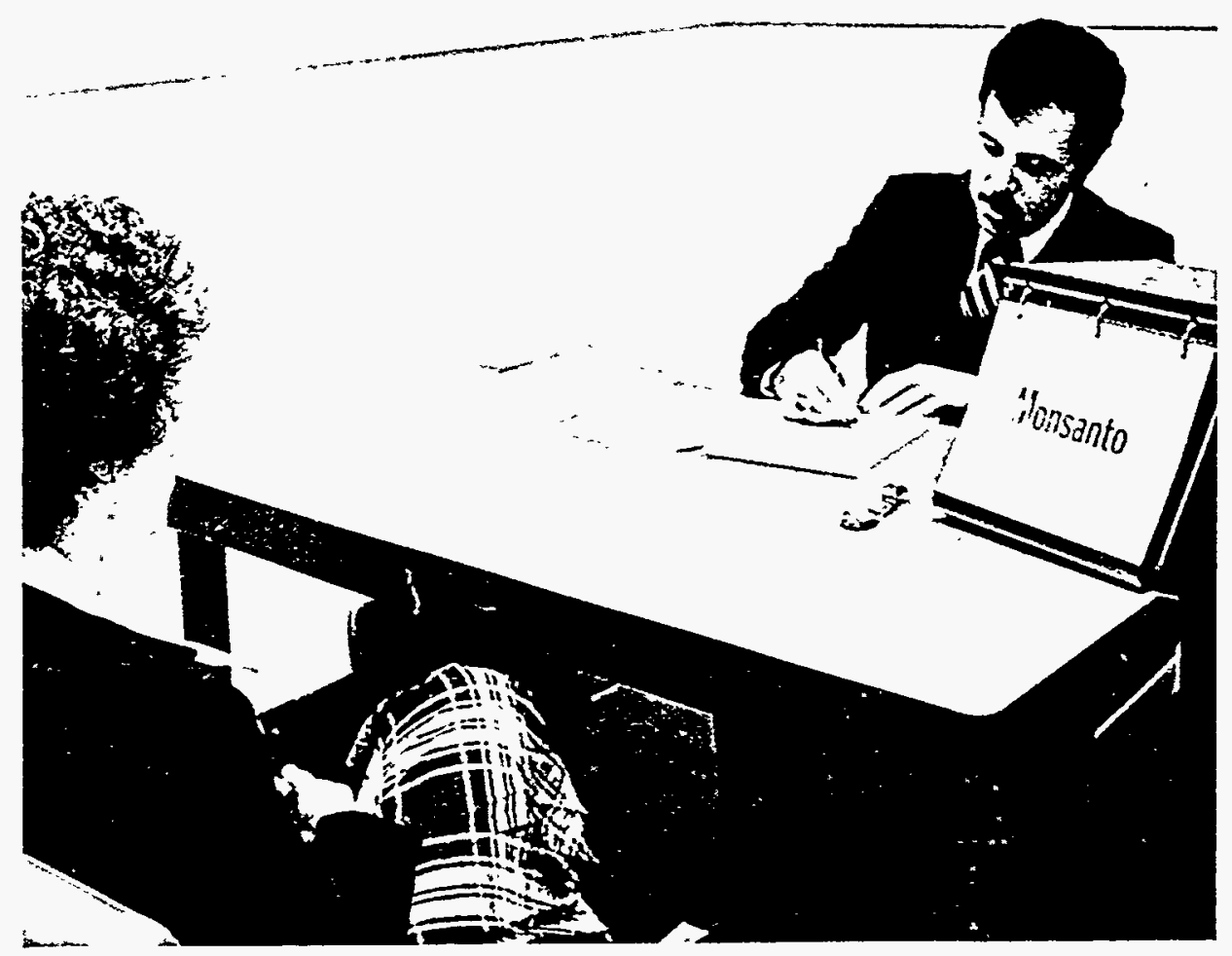

Chris Johnson (right), Selection and Placement Manager at Mound, interviews a potential ceramics employe at Alfred University, Alfred, N. Y. Ten college recruitment trips aimed at filling Mound jobs were made in 1978.

For our United Way campaign, 1978 was the most successful year ever. Donations of $\$ 52,062.12$ surpassed the goal and exceeded last year's contributions by more than $\$ 1,000$.

Representing Monsanto Company, Mound personnel presented Monsanto Fund cash awards to the University of Dayton Department of Chemical Engineering, and to an outstanding Miamisburg High School math and science student.

\section{Personnel}

Development of the human resource within the Facility was an important part of our activities in 1978. To this end, more than 60 supervisors from a broad range of specialties received training in professional interviewing techniques, and many professionals attended week-long courses in management technique and technical presentation development.

Under the auspices of the Mound Equal Opportunity Office, a successful career development instruction 

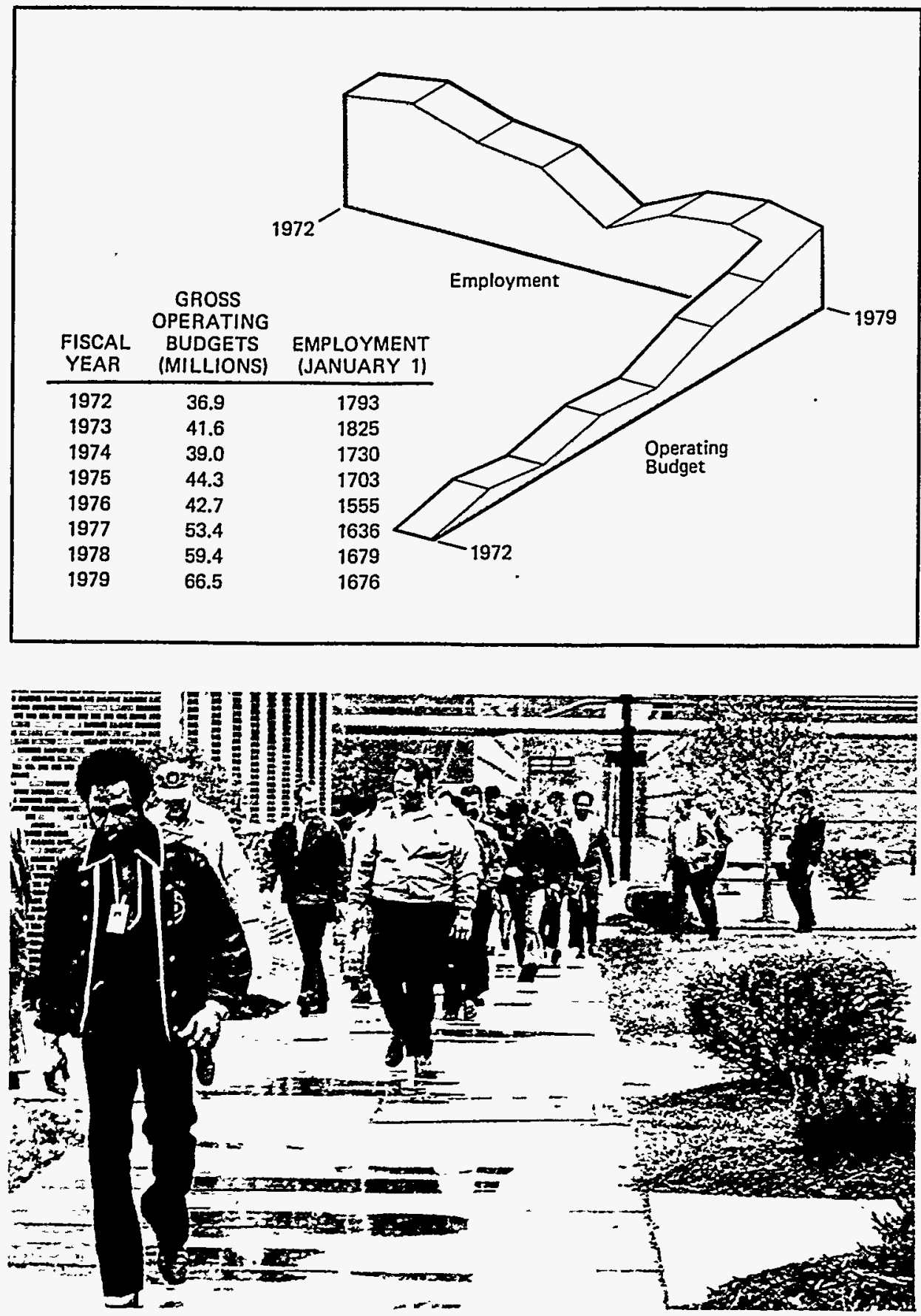

The number of people employed at Mound remained virtually constant from 1977

through 1978. program was implemented for nonexempt salaried minority, female, and handicapped employes. Designed to enhance the promotability of the 76 who attended, the sessions emphasized individual responsibility and typical career paths in Monsanto.

During the fall, we began an employe attitude survey which first covered salaried employes (to be followed by hourly employes in 1979). The survey will provide data on job satisfaction and the working climate of the Facility.

Fifteen women participated in a Maintenance Orientation Program aimed at female hourly employes interested in future employment in the maintenance trades. The program included a tour of maintenance facilities, a safety orientation by the Health Physics Department, and aptitude testing by the Ohio Bureau of Employment Services.

During 1978, five employes from the parent company transferred to Mound Facility, and seven Mound employes moved to other Monsanto operating companies. Seventy transfers and promotions occurred within the Facility itself. Our workforce totalled 1,676 at year-end, down three from 1977. One hundred and twenty-six salaried openings were filled in 1978. 


\section{People}

\section{Management}

Two major additions to our management staff occurred in 1978: V. Edward Castleberry became Director of Engineering, replacing acting Director Rene $C$. Herman, Jr.; and Thomas $M$. McGavick became Manager of Personnel, replacing Donald E. Kaldenberg. Both Castleberry and McGavick transferred to Mound from other Monsanto Company locations.

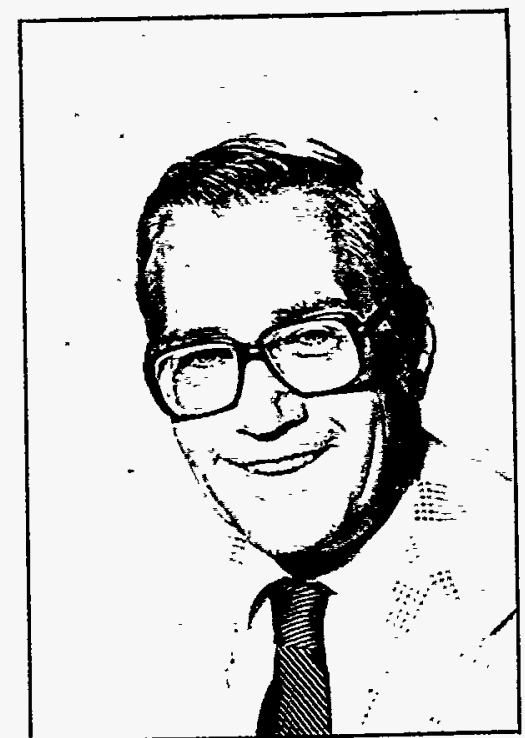

John R. McClain

Director

- Mound Facility

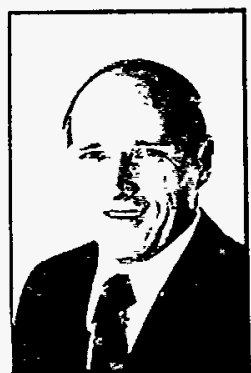

James E. Caldwell

Director

Finance

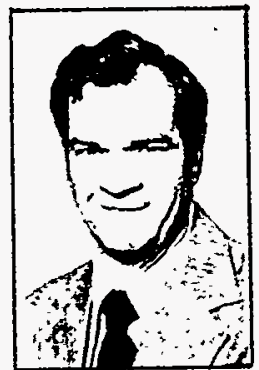

Thomas M. McGavick Manager Personnel

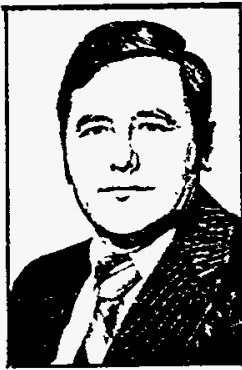

V. Edward Castleberry Director Engineering

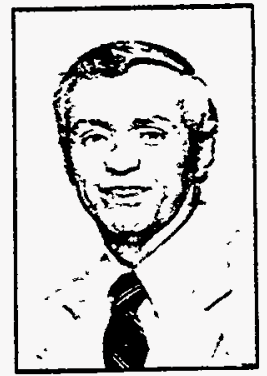

Morton L. Mullins Director

Administrative Services

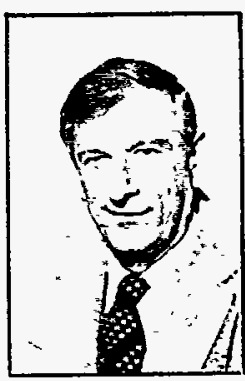

Robert T. Braun Director Advanced Devices

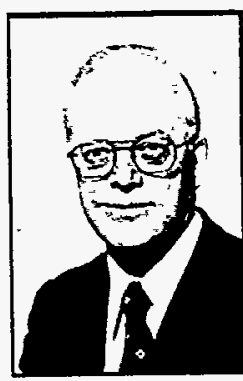

William T. Cave Director Nuclear Operations

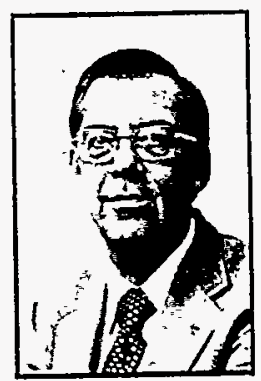
Director, Management Information \& Systems
Arthur F. Vollmer 